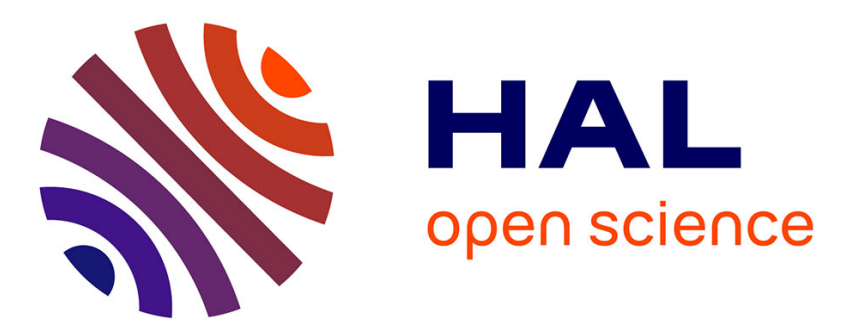

\title{
Damage of masonry structures relative to their properties: Development of ground movement fragility curves
}

\author{
Jamil Serhal, Olivier Deck, Marwan Al Heib, Fadi Hage Chehade, Dalia \\ Youssef Abdel Massih
}

\section{To cite this version:}

Jamil Serhal, Olivier Deck, Marwan Al Heib, Fadi Hage Chehade, Dalia Youssef Abdel Massih. Damage of masonry structures relative to their properties: Development of ground movement fragility curves. Engineering Structures, 2016, 113, pp.206 - 219. 10.1016/j.engstruct.2016.01.054 . hal01305171

\section{HAL Id: hal-01305171 \\ https://hal.univ-lorraine.fr/hal-01305171}

Submitted on 9 Dec 2017

HAL is a multi-disciplinary open access archive for the deposit and dissemination of scientific research documents, whether they are published or not. The documents may come from teaching and research institutions in France or abroad, or from public or private research centers.
L'archive ouverte pluridisciplinaire HAL, est destinée au dépôt et à la diffusion de documents scientifiques de niveau recherche, publiés ou non, émanant des établissements d'enseignement et de recherche français ou étrangers, des laboratoires publics ou privés. 


\title{
Damage of masonry structures relative to their properties: Development of ground movement fragility curves
}

\author{
Jamil Serhal ${ }^{\mathrm{a}, \mathrm{b}, *}$, Olivier Deck ${ }^{\mathrm{c}}$, Marwan Al Heib ${ }^{\mathrm{d}}$, Fadi Hage Chehade ${ }^{\mathrm{e}}$, Dalia Youssef Abdel Massih ${ }^{\mathrm{f}}$ \\ ${ }^{a}$ Université de Lorraine, CNRS, CREGU, GeoRessources Laboratory, Nancy F-54042, France \\ ${ }^{\mathrm{b}}$ Centre de Modélisation, EDST, Université Libanaise, Lebanon \\ ${ }^{\mathrm{c}}$ Ecole des Mines de Nancy, Université de Lorraine, CNRS, CREGU, GeoRessources Laboratory, Nancy F-54042, France \\ ${ }^{\mathrm{d}}$ INERIS - Direction de Risques du Sol et du Sous-Sol, CAMPUS ARTEM, Ecole des Mines de Nancy, Nancy F54042, France \\ e Université Libanaise, Centre de Modélisation, Ecole Doctorale des Sciences et Technologies, Beyrouth E IUT, Saida, Lebanon \\ ${ }^{\mathrm{f}}$ Université Libanaise, Faculté de Génie Branche II Roumieh, Lebanon
}

The objective of this paper is to study the effect of the properties of masonry buildings on the threshold values of the deflection ratio, which is used to assess the damage category of buildings. Based on the results obtained from a sensitivity analysis, fragility curves are drawn and used to develop a probabilistic approach to help assess the damage for different structure typologies due to ground settlement.

The threshold values of the building deflection ratio are primarily empirical. The analytical method of Burland et al. (1977) was used to define analytical threshold values to assess the building damage in relation to the building properties: length $L$, height $H$, equivalent Young's modulus $E$ and equivalent shear modulus $G$. This paper starts with a comparison of various empirical and analytical threshold values of the deflection ratio. Next, a sensitivity analysis is performed using the analytical method of Burland et al. (1977) and modified by Saeidi et al. (2012) to take into account the anisotropic behaviour associated to the masonry mechanical properties and the existence of openings. The investigated parameters are the $E / G$ and $L / H$ ratios and the position of the neutral axis of the beam simulating the building. The results show a significant influence of the $E / G$ and $L / H$ ratios and suggest defining a range of the threshold deflection ratio associated to different damage categories for different building typologies. Fragility curves are then developed based on the definition of the building typologies. These fragility curves are a useful tool to estimate the probability of reaching each category of damage once the deflection ratio and the properties of the relative structure are determined. To improve their accuracy, several intervals of the properties of the buildings were used to develop these fragility curves. The choice of these intervals to draw the fragility curves was based on various bibliographic studies and numerical studies in the case of $E / G$ and statistic studies in the case of $L / H$.

\author{
Keywords: \\ Masonry \\ Building \\ Damage \\ Threshold \\ Deflection ratio \\ Fragility curves
}

\section{Introduction and objectives}

Many ground movements can occur due to different natural and manmade hazards (subsidence, landslides, consolidation...) and induce a differential settlement of the buildings. As many existing and new recent structures are composed of masonry, this paper focuses on the damage of the masonry buildings caused by such movements. As a result of the differential settlement of the build-

* Corresponding author at: Université de Lorraine, CNRS, CREGU, GeoRessources Laboratory, Nancy F-54042, France. Tel.: +33 624202877.

E-mail addresses: jamil.serhal@univ-lorraine.fr, serhal_jamil@hotmail.com (J. Serhal), olivier.deck@mines-nancy.univ-lorraine.fr (O. Deck), Marwan.alheib@ ineris.fr (M. Al Heib), fchehade@ul.edu.lb (F.H. Chehade), dalia.abdelmassih@ul.edu. lb (D. Youssef Abdel Massih). ings, these masonry structures may be subjected to damage, whose levels may vary from simple cracking to partial or total collapse. The severity of the damage is assessed relative to many parameters noted in terms of the threshold parameters. The damage category may be estimated after the damage occurs in the building using different parameters, such as crack widths. As a consequence, correlations are observed between the damage category and the building movements, as the deflection ratio and some threshold values of those movements may be provided to categorise the damage and qualify the level of damage. These values may then be used to assess the damage due to a predicted future ground movement. However, many different threshold values can be found, and the selection of the good ones for a given building is a challenging problem. The first objective of this paper is to show 
the consistency of the threshold values of the deflection ratio and to justify some of the relationships used to define the threshold values of this parameter in relation to the building properties. As a consequence, the damage assessment for a given deflection ratio must be seen as uncertain. The problem raised by the uncertainties for the assessment of building damage is addressed in other fields, such as in seismic engineering [1,2], volcanic engineering [3], mining engineering [4] and risk analysis related to floods. In these fields, vulnerability and fragility curves are used to assess the average damage, and the damage distribution for all buildings with similar characteristics, as a function of the event intensity. This approach has proven to be a good compromise between the accuracy of the results and the investment of time and money required for the studies. The development of such a method in the field of differential settlement would represent a significant innovation. It is the second objective of this paper.

The methodology developed in this paper is as follows:

First, a comparison between the threshold values of the deflection ratio for different damage categories given in the literature is presented to show their consistency. A figure summarising the threshold values of the deflection ratio given by many authors is provided.

Next, a sensitivity analysis is performed to highlight the range of variation of the threshold values of the deflection ratio relative to the properties of the structure. The analytical method of Burland et al. [5] was adopted to calculate the values of the deflection ratio thresholds as a function of the building properties. In this analytical method, Burland et al. [5] assimilates the masonry wall to a single simply supported beam subjected to a differential settlement. A relation is then provided between the deflection ratio and the maximum tensile strain in the building. The damage categorisation is based on the thresholds of the limiting tensile strain.

Finally, this paper will provide a new diagram of thresholds of the deflection ratio with a wide range of variation, depending on the building properties. The question of uncertainties when assessing the building damage is then addressed. The fragility curves are developed. These curves may then be used for a probabilistic assessment of the building damage category as a function of its deflection ratio.

\section{Damage assessment methods - thresholds of the deflection ratio}

\subsection{Introduction}

Many authors have studied the subject of the masonry building damage due to ground movements [5-9]. Refs. [5-7] studied the damage of the buildings in function of the deformation in the structure. This damage was related to many parameters relative to the movement of the building. Burland et al. [5] related the damage to the deflection ratio, Boscardin and Cording [6] related the damage to the distortion of the building, and Boone [7] related the damage to the cumulative length of the cracks appearing in the building. Giardiana et al. [8] studied the effect of the soil struc- ture interaction, the building, and the profile of the settlement on the structural damage in terms of cracking and distortion. Hong [9] investigated the effect of the infill masonry on the damage. Due to these studies and many other authors, different categories of damage of the masonry structures are also provided. The number and the description of these damage categories may vary from an author to another, depending on the parameters used to assess the damage. Table 1 presents a comparison of the scales of damage proposed by numerous authors [10]. Burland et al. [5] gave a system of classification based on "ease of repair" and crack width in order to assess the damage. It must be specified that the key factor in defining damage is 'ease of repair'. The crack width is only one aspect in determining the level of damage and should not be used as a sole measure of it. In addition, Burland et al. [5] used the limiting tensile strain as a serviceability parameter. Bhattacharya and Singh [11] distinguished the functional and the structural degradations, while Pellisier et al. $[12,13]$ used the crack width without distinguishing those cracks related to the structural elements of the building. Ji-Xian [14] and Bruhn et al. [15] studied the reparation required after the damage relative to the cracks appearing in the structure.

This paper will consider the scale of Burland et al. [5]. The analytical method developed by Burland et al. [5] is based on the relationship between the deflection ratio thresholds and the principle strain in the building, which indicates the onset of cracking in the structure.

\subsection{Thresholds of the deflection ratio}

When settlement occurs, the building represented by $A B$ in Fig. 1 will adopt a new position, represented by the curve $A^{\prime} B^{\prime}$, and deflection $\Delta$ is observed. The deflection ratio is the ratio between the maximal building deflection and the building length, with the straight line between the two building edges considered as the reference of the zero deflection case (Fig. 1).

Many threshold values of the deflection ratio were provided in the bibliographic references, depending on the type of the building. Mine subsidence engineering [16] gathered, for 17 types of buildings, the allowable values of the deflection ratios provided by a number of sources. As a result, the allowable deflection ratio for the masonry buildings may vary from a maximum of $1 / 300$ for reinforced masonry to a minimum of $1 / 4000$ for solid masonry. This allowable deflection ratio is the deflection ratio that causes only a slight impact (D2 in Table 1, Burland's scale).

Fig. 2 compares the different threshold values of the deflection ratio reported by different sources, such as Burland [17], Bhattacharya and Singh [11], Ricceri and Soranzo [18], Mine Subsidence Engineering [16], and Kleipikov [19] relative to each damage category. This figure shows that these threshold values for the deflection ratio vary by author. These threshold values of the deflection ratio change as a function of the building properties. In fact, the relationship between the properties of the building and the damage category is rarely studied. This paper addresses this issue to

Table 1

Comparison between the different damage scales - [10].

\begin{tabular}{|c|c|c|c|c|c|}
\hline Stacey and Baker [35] & Bhattacharya and Singh [11] & Pellisier et al. [13] & Ji-Xian [14] & Bruhn et al. [15] & Burland [5] \\
\hline \multirow[t]{3}{*}{ Superficial } & Architectural & No cracks & 1 & Slight & Negligible (D0) \\
\hline & & Negligible & 2 & & Very slight (D1) \\
\hline & & Very weak to weak & & & Slight (D2) \\
\hline \multirow[t]{3}{*}{ Issues } & Functional & Mean to important & 3 & Moderate & Moderate (D3) \\
\hline & & & & Severe & Severe (D4) \\
\hline & Structural & Very important & 4 & Very severe & Very severe (D5) \\
\hline
\end{tabular}




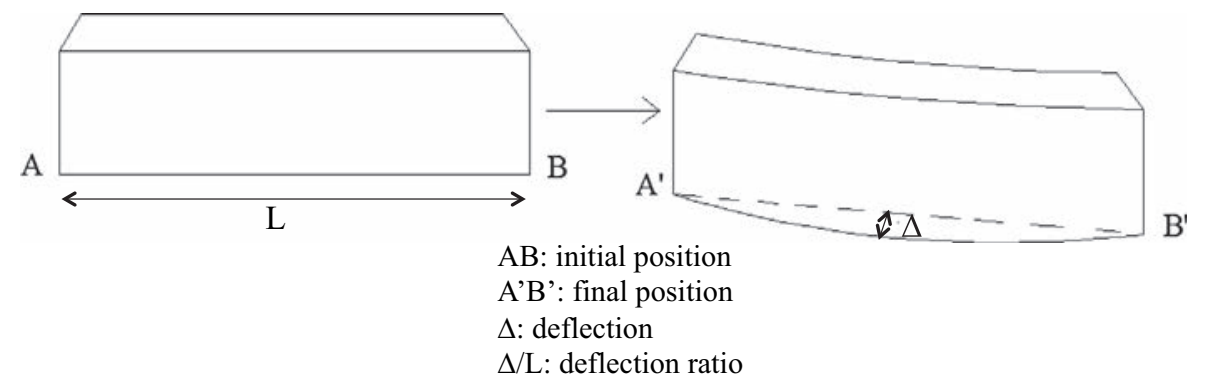

Fig. 1. Definition of the deflection ratio of a structure due to a deferential settlement.

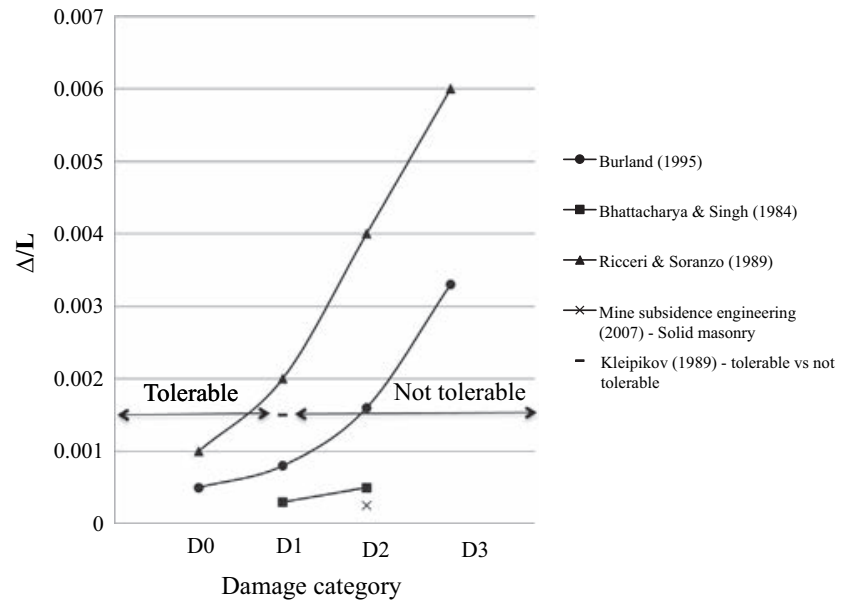

Fig. 2. Thresholds of the deflection ratio for building structures.

clarify the relationship between the properties of the building and the deflection ratio.

\subsection{Burland's method - approach of a simple beam}

Burland and Wroth [20] noted that the tensile strain might be a fundamental parameter in determining the onset of cracking, based on the concept of the simple elastic beam, which can be used to develop deflection criteria for the onset of visible damage. This approach based on a simple beam provides considerable insight into the mechanisms of controlling cracking. Therefore, in many circumstances, it is both reasonable and instructive to represent the facade of a building by means of a simple homogeneous rectangular beam of length $L$ and height $H$ (Fig. 3 ).

Burland et al. [5] replaced the concept of the critical tensile strain by that of the limiting tensile strain. This limiting tensile strain is used as a serviceability parameter that can vary to take into account the different serviceability states. The authors have distinguished two extreme modes of deformation of the beam in the definition of the strain distribution within it. These two extreme modes are bending about a neutral axis and shearing.
They provided equations relating the deflection ratio to the maximal tensile strain in the bending area (mid-span section) and shear area (near edges) with respect to the building properties (Eqs. (3) and (4)). The maximal strain is then calculated (Eq. (6)) and compared with the limiting tensile strain values (Table 2 ). At this point, the assessment of damage of the masonry buildings is conducted.

Eqs. (1)-(6) are related to this method. These equations are also used in the sensitivity analysis performed in this paper:

$I=K H^{3}$

$K=\left[\frac{1}{12}+\left(\frac{1}{2}-\kappa\right)^{2}\right]$

$\left(\frac{\Delta}{L}\right)_{\text {bending }}=\left(\frac{5 L}{48 H}+\alpha K \frac{E}{G} \frac{1}{L / H}\right) \epsilon_{\mathrm{bmax}}$

(uniformly distributed load, neutral axis at the bottom)

$$
\begin{aligned}
\left(\frac{\Delta}{L}\right)_{\text {bending }}= & \left(\frac{10 L}{48 H}+\alpha K \frac{E}{G} \frac{2}{L / H}\right) \epsilon_{\mathrm{bmax}} \\
& \text { (uniformly distributed load, neutral axis at the middle axis }
\end{aligned}
$$

$\left.\left(\frac{\Delta}{L}\right)_{\text {shear }}=\frac{1}{2}+\frac{7,5}{144} \frac{1}{E / G} \frac{1}{\alpha} \frac{1}{K}\left(\frac{L}{H}\right)^{2}\right) \epsilon_{\mathrm{dmax}}$ (uniformly distributed load)

$\epsilon_{\max }=\max \left(\epsilon_{\mathrm{dmax}}, \epsilon_{\mathrm{bmax}}\right)$

where $\Delta / L$ (bending and shear) is the deflection ratio that respectively leads to the maximal tensile strains in the bending $\varepsilon_{\mathrm{bmax}}$ and the shear areas $\varepsilon_{\mathrm{dmax}}, I$ the inertia of the section, $\Lambda$ a parameter to describe the position of the neutral axis, $L$ the length of the building, $H$ the height, $E$ the Young's modulus, $G$ the shear modulus and $\alpha$ the ratio of the maximum shear stress and the average shear stress $(\alpha=3 / 2$ for a rectangular section). Eqs. (3)-(5) are relative to bending ( 3 and 4 ) and shear (5) strain; the use of these equations is based on Burland's differentiation between two critical areas in the building: the shear critical area and the bending critical area. Fig. 4 shows the position of the neutral axis in the beam; it is described by the parameter $\Lambda$. Here, $\Lambda=0.5$ corresponds to a neutral

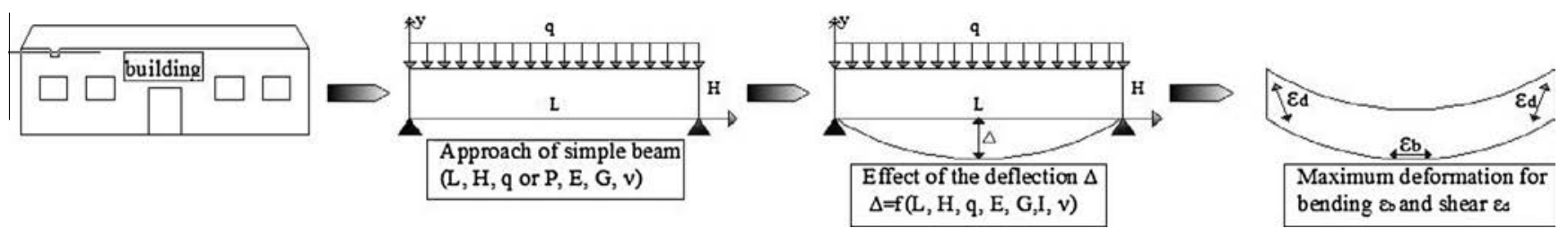

Fig. 3. Principle of Burland's method of damage assessment - after Saeidi [21]. 
Table 2

Severity of building damage - after Burland et al. [5]

\begin{tabular}{|c|c|c|c|}
\hline Damage category & Description of typical damage & Typical Crack width & $\begin{array}{l}\text { Limiting tensile } \\
\text { strain } \varepsilon_{\lim }(\%)\end{array}$ \\
\hline Negligible (0) (D0) & Hairline cracks & $<0.1 \mathrm{~mm}$ & $0-0.05$ \\
\hline Very slight (1) (D1) & $\begin{array}{l}\text { Very slight damage includes fines cracks that can be easily treated during normal decoration, } \\
\text { perhaps an isolated slight fracture in the building, and cracks in the external brickwork that } \\
\text { are visible on close inspection }\end{array}$ & $1 \mathrm{~mm}$ & $0.05-0.075$ \\
\hline Slight (2) (D2) & $\begin{array}{l}\text { Slight damage includes cracks that can be easily filled and probably require redecoration, } \\
\text { several slight fractures that may appear to show the inside of the building, cracks that are } \\
\text { visible externally and may required some re-pointing, and doors and windows that may stick }\end{array}$ & $<5 \mathrm{~mm}$ & $0.075-0.15$ \\
\hline Moderate (3) (D3) & $\begin{array}{l}\text { Moderate damage includes cracks that require some opening up and can be patched by a } \\
\text { mason, recurrent cracks that can be masked by suitable linings, re-pointing of external } \\
\text { brickwork (and possibly requiring a small amount of brickwork replacement), doors and } \\
\text { windows that stick, service pipes that may fracture, and impairment of weather-tightness }\end{array}$ & $\begin{array}{l}5-15 \mathrm{~mm} \text { or a number of } \\
\text { cracks }>3 \mathrm{~mm}\end{array}$ & $0.15-0.3$ \\
\hline Severe (4) (D4) & $\begin{array}{l}\text { Severe damage includes large cracks requiring extensive repair work involving breaking-out } \\
\text { and replacing sections of walls (especially over doors and windows), distorted windows and } \\
\text { door frames, noticeably sloping floors, leaning or bulging walls, some loss of bearing in } \\
\text { beams, and disrupted service pipes }\end{array}$ & $\begin{array}{l}15-25 \mathrm{~mm} \text { depending on } \\
\text { the number of cracks }\end{array}$ & $>0.3$ \\
\hline Very severe (5) (D5) & $\begin{array}{l}\text { Very severe damage often requires a major repair job involving partial or complete } \\
\text { rebuilding, beams lose their bearing, walls lean and require shoring, windows are broken } \\
\text { with distortion, and a danger of structural instability exists }\end{array}$ & $>25 \mathrm{~mm}$ & \\
\hline
\end{tabular}

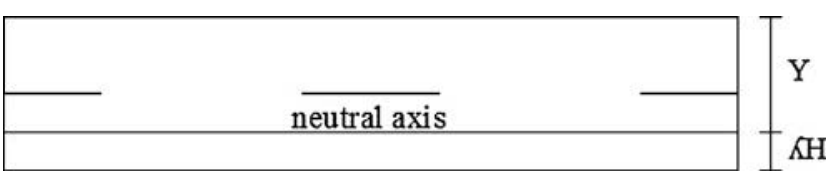

Fig. 4. Beam section and the position of the neutral axis.

axis situated at the middle axis, and $\Lambda=0$ represents a neutral axis situated at the bottom. The position of the neutral axis depends on the real geometry and homogeneity of the structure and the soil structure interaction. $K$ is a factor that depends on the position of the neutral axis defined by $\Lambda . \varepsilon_{\max }$ is the maximal tensile strain in the beam used to assess the damage, when compared to the limit tensile strain noted in Table 2 . When the maximal strain $\varepsilon_{\max }$ matches a given value of the maximal allowable strain $\varepsilon_{\lim }$ (Table 2), the equivalent threshold of the deflection ratio is the minimum value between the values of bending and shear computed using Eqs. (3)-(5).

Burland et al. [5] provided six categories of damage with the associated value of the limiting tensile strain. These categories are the same as those presented in Table 1 and are numbered from 0 to 5 . These categories are divided among the slight damage categories 0 and 1 , the aesthetic damage category 2 , the serviceability damage in categories 3 and 4, and finally category 5, which represents the damage affecting the stability (Table 2). Note that the
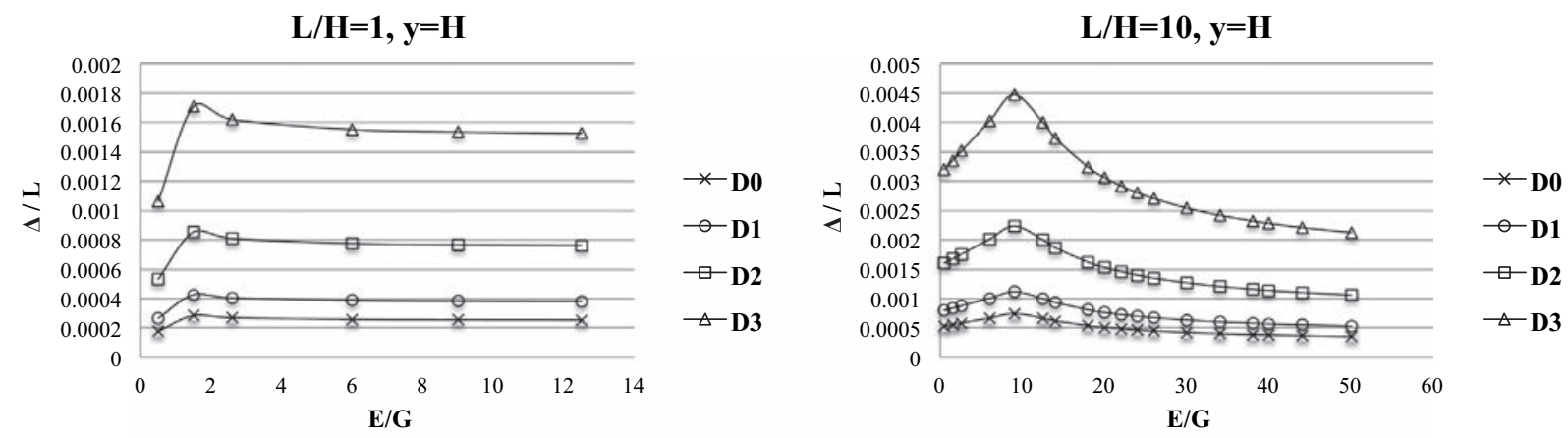

(A) effect of the variation of $\mathrm{E} / \mathrm{G}$ on the thresholds of the deflection ratio, relative to the values of $\mathrm{L} / \mathrm{H}-\mathrm{y}=\mathrm{H}$ refers to a neutral axis at the bottom of the beam section

$E / G=2.6$

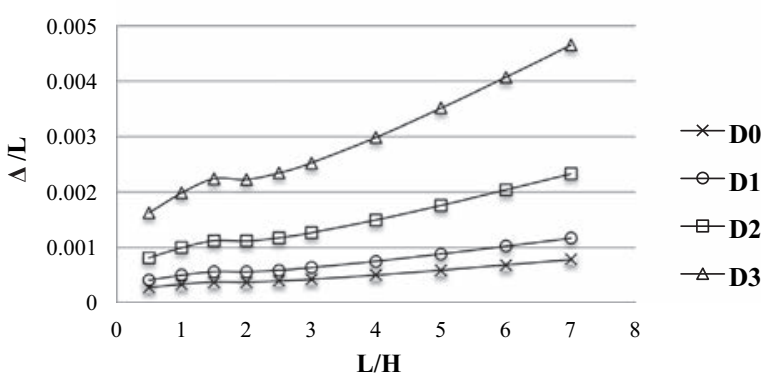

(B) influence of $\mathrm{L} / \mathrm{H}$ on the threshold values of the deflection ratio
$\mathrm{L} / \mathrm{H}=\mathbf{1}, \mathrm{y}=\mathrm{H} / \mathbf{2}$

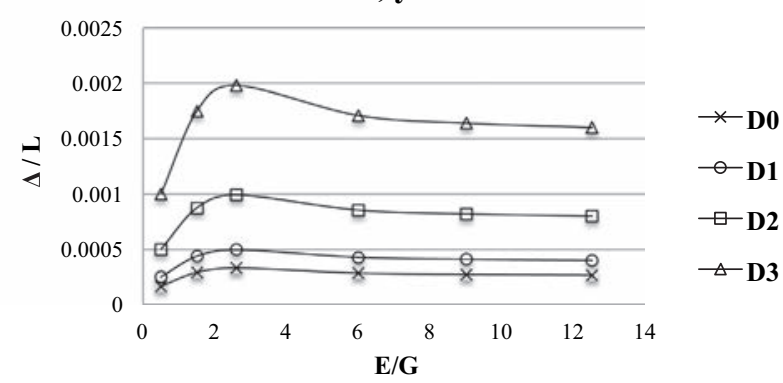

(C) influence of the position of the neutral axis (comparing A and C) $\mathrm{y}=\mathrm{H} / 2$ refers to a neutral axis at the middle axis of the beam section

Fig. 5. Effect of the $(E / G)$ and $(L / H)$ ratios and the position of the neutral axis on the thresholds of the deflection ratio for the different damage categories. 


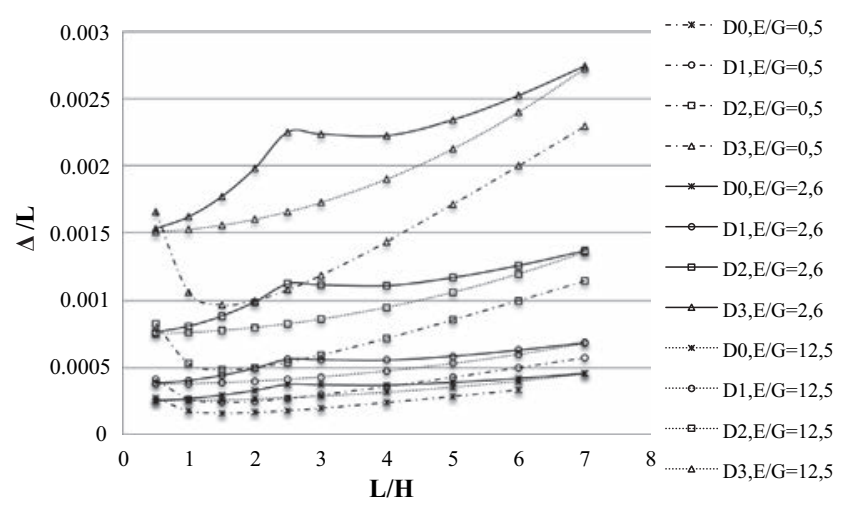

Fig. 6. Thresholds of the deflection ratio $\Delta / L$ as a function of $L / H$ for different damage categories and for different values of $E / G$.

damage categories 4 and 5 are relative to the same value of the tensile strain $\varepsilon_{\text {lim. }}$. Note that the main factor is the ease of repair, when the crack width noted in this table is just one aspect of the damage.

\section{Analytical analysis}

This section focuses on an analytical method to study the threshold values of the deflection ratio of a masonry building relative to its properties.

\subsection{Description of the sensitivity analysis}

The analytical study of the paper is based on the method of Burland et al. [5]. The analysis of Eqs. (1)-(6) and Fig. 4 enables the identification of the geometrical and mechanical parameters that can be studied to assess their influence over the deflection ratio of a masonry building associated with a given damage category level ranging from D0 to D5.

The sensitivity analysis is based on the variation of the geometric properties (length-to-height ratio, $L / H$ ) and the variation of the mechanical properties of the masonry buildings (ratio of the Young's modulus to the shear modulus, $E / G)$ [22-25]. The effect of the position of the neutral axis in the beam section is also studied.
The Young's-to-shear modulus ratio $E / G$ may vary within a very large range. Son and Cording [22] presented the results of a 2D numerical analysis using the distinct element method to assess the equivalent bending stiffness and the shear stiffness of a masonry wall, taking into account the anisotropy of the masonry and the percentage of openings in the wall. They studied the effect of the ratio of shear stiffness to normal stiffness of the joints between the masonry elements (blocks) and the percentage of openings on the ratio of the Young's modulus to the shear modulus of the equivalent beam. They compared the results with field data and analytical calculations using the method of Singh [24]. The results demonstrated that increasing the percentage of openings decreases the value of the equivalent Young's modulus and the equivalent shear modulus. They concluded that the ratio of the equivalent Young's modulus to the equivalent shear modulus $E / G$ may vary greatly, reaching up to a large value of 52 . Such a value is impossible if considering an isotropic behaviour of the equivalent beam because the $E / G$ should then be limited to $2(1+v)$ in isotropic behaviour, where $v$ is the Poisson ratio of the beam material. However, it is possible if a transversely isotropic behaviour is considered. Thus, Saeidi et al. [23] justified that the formulas of Burland et al. [5] may be used for large values of the ratio $E / G$. In addition, Son and Cording [22] demonstrated that shear deformation controls the onset of cracking for low ratios of length to height $(L / H)$. Details of the study of Son and Cording [22] are presented in the sections below when describing the methodology used to draw the fragility curves. $L / H$ and $E / G$ respectively variations of up to 8 and 52 were considered in this sensitivity analysis. Note that ratios of $L / H$ less to 2 are not taken into account because this sensitivity analysis is based on beam theory.

In addition, because this method uses beam theory, the position of the neutral axis may be questionable. Burland and Wroth [20] and Boscardin and Cording [6] argued that if the building is subjected to a hogging deformation, then the neutral axis can be located at the bottom of the beam due to the low tensile strength of the building upper floors and its value at the foundations. Boone $[7,25]$ noted the influence of the floors and the roof, which may increase the tensile strength and thereby the position of the neutral axis to the middle axis. In the case of a sagging deformation, the neutral axis is in fact the same as the average fibre position. To understand the effect of the position of the neutral axis, two positions of the neutral axis are taken into account in this

\begin{tabular}{ll} 
tolerable & Not tolerable \\
\hline 0.0015 & Klepikov (1989)
\end{tabular}

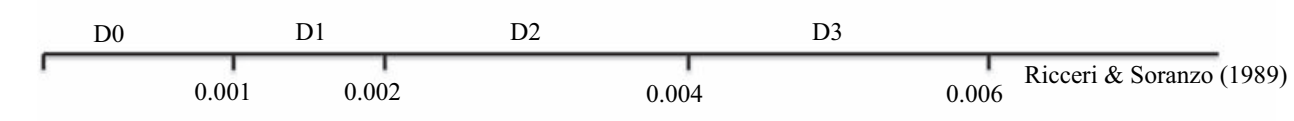

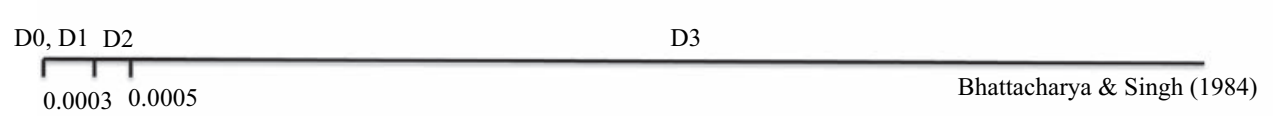

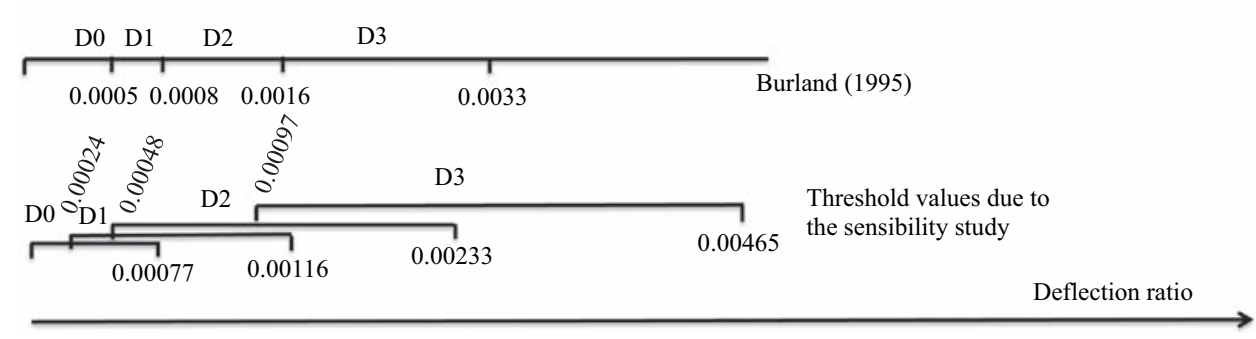

Fig. 7. Thresholds of the deflection ratio diagram and the damage classification diagram for $0.5<E / G<52$ and $2<L / H<8$. 


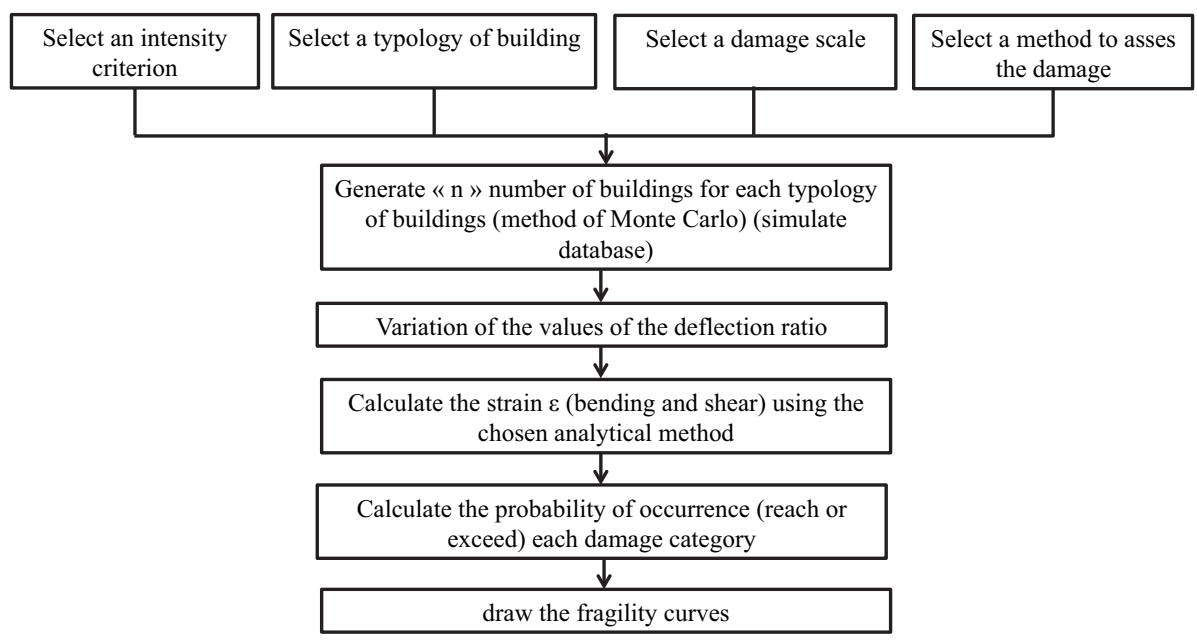

Fig. 8. Steps followed to draw fragility curves.

sensitivity analysis: a neutral axis situated in the middle of the beam, denoted $y=H / 2$, and a neutral axis located at the bottom of the beam, denoted $y=H$.

\subsection{Results of the sensitivity analysis}

Fig. 5 presents the results of the sensitivity analysis. The presented curves in Fig. 5 are the thresholds of deflection ratio relative to each damage category. All these curves present a maximum peak point for each damage category. This peak point represents the transition between the two critical areas of bending and shear. The position of this peak point and its significance (from the critical shear area to the bending critical area and vice versa) will be described in the following paragraphs.

The sensitivity study on the effect of the ratio of the Young's modulus to the shear modulus $E / G$ showed that, beyond a specified value of the $E / G$ ratio, this ratio no longer has an effect on its damage categorisation. In other words, a horizontal plateau of the deflection ratio curves as a function of $E / G$ was observed (Fig. 5A). However, this specified value of $E / G$ varies with respect to the $L / H$ ratio of the building. As the $L / H$ ratio of the building increases, this specified value of $E / G$ - that at which the effect of $E / G$ becomes negligible - is found to increase. Beyond this value, $E / G$ remains meaningless for the deflection ratio values, i.e., the Young's modulus to shear modulus ratio of a masonry building is increasingly influential as the length to height ratio increases. For example, no influence of $E / G$ is found for $E / G>2.6$ for $L / H=1$, and no influence of $E / G$ is found for $E / G>20$ for $L / H=5$ (Fig. 5A).

The variation of the length to height ratio, $L / H$, showed that the geometry of the masonry building has a great effect, especially when increasing the severity of the damage (D2 and D3) (Fig. 5B). In other words, the greater is the $L / H$ ratio, the greater is the influence of the bending state of the building on its threshold of deflection ratio. The curve of the deflection ratio as a function of the $L / H$ ratio appears to have a vertical slope for increasing $L / H$.

The peak point represents the passage between the two critical areas of bending and shear. In Fig. 5A, the peak point is related to the passage from the critical bending area to the critical shear area with increasing the $E / G$ ratio. In Fig. $5 \mathrm{~B}$, the peak point relates the passage from the maximal strain in the shear area to the bending area. This peak point occurs at higher values of $E / G$ ratio as the $L /$ $H$ ratio is increased. The position of this peak point was affected by the position of the neutral axis. This peak point occurs for equal values of $E / G$ and $L / H$ for a neutral axis positioned at the bottom of
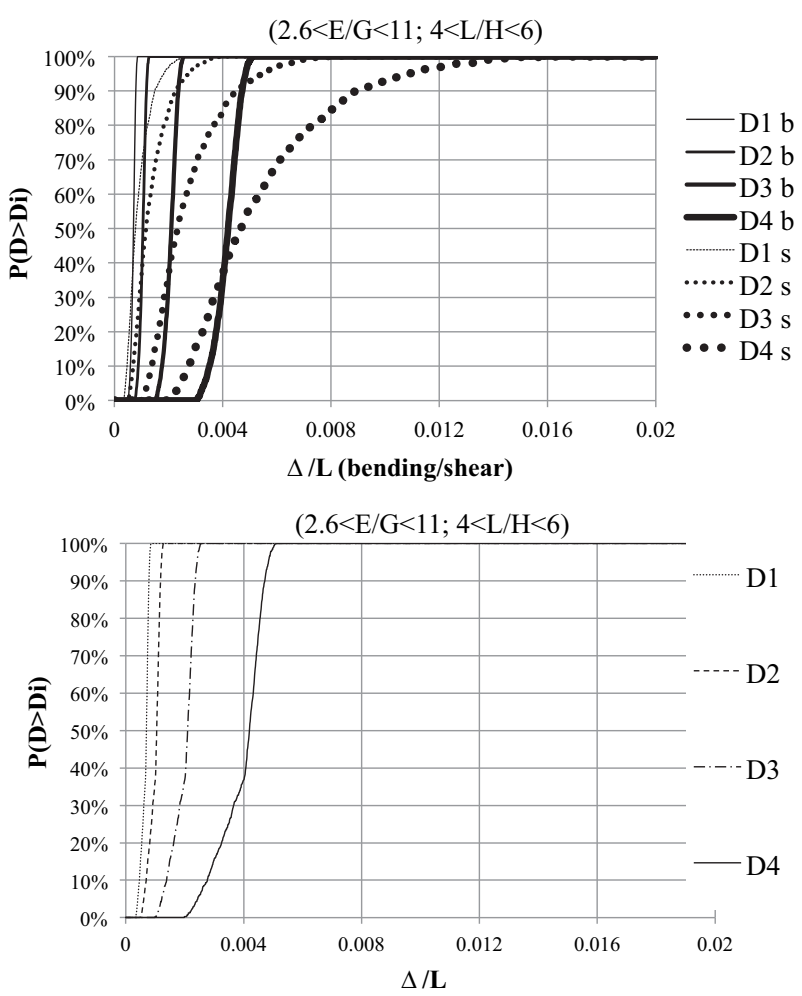

Fig. 9. Example of fragility curves drawn for: (a) both bending (subscript b) and shear states (subscript s) for case 1-a and (b) the resulting envelope.

the beam (Fig. 5A). For a neutral axis positioned at the middle axis of the beam (Fig. 5C), this peak point occurs when the value of $E / G$ is twice that of $L / H$.

The position of the neutral axis has a small influence on the values of the deflection ratio. The neutral axis position mainly affects the position of the maximum peak point of each curve, as noted previously. This result, which shows the effect of the position of the neutral axis on the position of the peak point, can be obtained analytically as well by equating the equations relative to the computation of the deflection ratio in the shear area and the bending area, once for a neutral axis at the bottom of the section of the beam and once for a neutral axis at the middle axis of the beam section. 
Table 3

Geometrical description of the buildings relative to the $L / H$ ratio.

\begin{tabular}{ll}
\hline$L / H$ ratio & Description \\
\hline $2-4$ & Medium horizontal slenderness \\
$4-6$ & Large horizontal slenderness \\
$6-8$ & Very large horizontal slenderness \\
$>8$ & Buildings of exceptional horizontal slenderness \\
\hline
\end{tabular}

\subsection{Intersection of damage scales due to the sensitivity analysis}

As a result of the sensitivity analysis $(E / G, L / H$, and the position of the neutral axis), for the same value of the deflection ratio, many damage categories seem to occur, depending on the mechanical and the geometrical properties of the building. In other terms, two buildings having different properties may exhibit a different level of damage severity, even if they are subjected to the same settlement. In addition, for the same value of the $L / H$ ratio, many thresholds of deflection ratio are found to exist relative to the value of the $E / G$ ratio. Fig. 6 shows the curves of the threshold of the deflection ratio values for each damage category for three chosen values of the studied interval of $E / G$ that reaches 52 . The three chosen values of $E / G$ in Fig. 6 are 0.5, 2.6 and 12.5. Saeidi [21] suggested that the smallest value of $E / G$ represents a building with reinforced load bearing walls and a very small percentage of openings. He also suggested that a value of $E / G$ equal to 2.6 represents an isotropic assumption of the masonry, with a Poisson's coefficient equal to 0.3 . In addition, a value of $E / G$ equal to 12.5 represents a masonry building with a number of openings (windows and doors) or a frame building. Lastly, a comparison of the minimum and the maximum threshold values obtained by this parametric study with those shown in (Fig. 2) is conducted. A correlation is observed between the thresholds of the deflection ratio of the literature and those obtained by the present parametric study. In addition, an overlap appears in Fig. 7. This overlap indicates that the properties of the building have a great importance in assessing its damage category. The thresholds of the deflection ratio provided in the bibliographic references must be considered as particular values relative to specific buildings properties, i.e., for each damage category, a range of variation of the thresholds of the deflection ratio appears, depending on the mechanical and geometrical properties of the masonry building. In addition, two buildings having different properties exhibit different damage severities, even if they are subjected to the same settlement. However, both dimensions and mechanical properties of the beam used to assess the damage of a real building may be seen as uncertain values. A possible means of accounting for this uncertainty is to develop fragility curves associated to different building types. These curves provide the probability of reaching each damage category related to the values of the deflection ratio as a function of the uncertain properties of the building type. These curves are provided in the next section of this paper.

\section{Fragility curves for damage assessment}

As previously seen, a variability of the damage for the same deflection ratio can be observed. This is the consequence of heterogeneities in the mechanical and geometrical properties of the masonry structures. As a consequence, the damage assessment for a given deflection ratio must be seen as uncertain and fragility curves are an effective way to represent this uncertainty. Such a way was already investigated by Giardiana et al. [26], who developed damage functions of masonry buildings based on numerical modelling. They particularly investigate the influence of the percentage of opening in the building and some mechanical properties of the masonry as the Young's modulus and tensile strength. Their

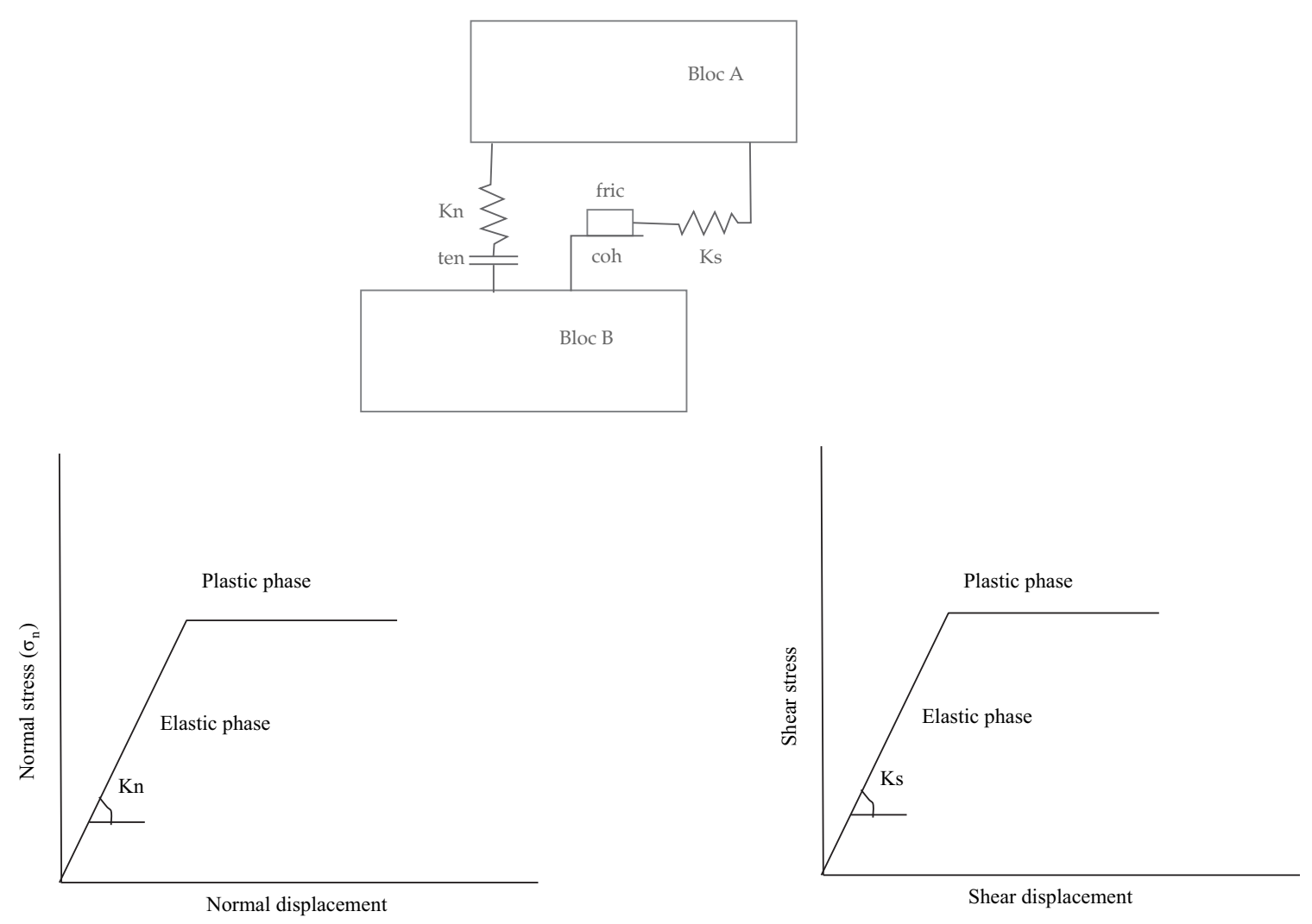

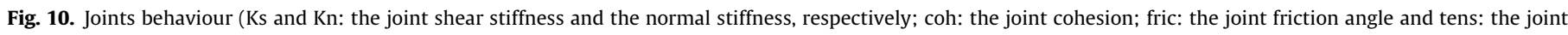
tensile strength). 


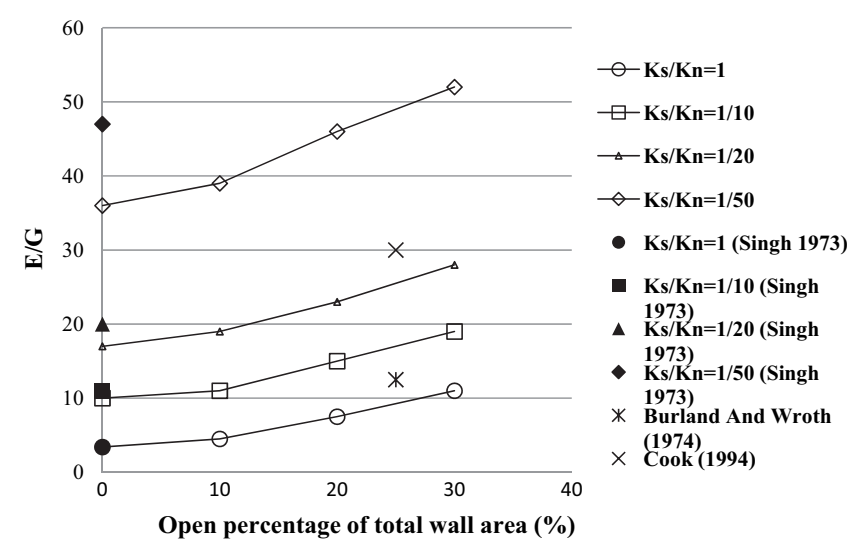

Fig. 11. Relationship between the ratio of the equivalent Young modulus to the equivalent shear modulus and the open percentage of total wall area for different values of the Ks/Kn ratio - after [22-32].

results appear very useful to assess influence of parameters. However, they didn't address the question of uncertainties which is the goal of this section.

Consequently, this section presents the methodology followed to draw fragility curves that estimate the probability of a building being classified in a specified category of damage, once the deflection ratio and the building typology are known. After that, a typology for masonry structures is defined in Section 5, and the fragility curves relative to different cases of masonry buildings are presented and discussed.

\subsection{Concept of the fragility curves - intervals of $E / G$ and $L / H$}

Fragility curves provide the probability $P(D>$ Di) for each known value of the deflection ratio, where $D$ is the building damage and Di refers to each damage category. The fragility curves may be developed for different building types and can be used to take into account some uncertainties about the damage assessment.

The development of fragility curves is first based on the definition of a building typology. Each building type must be described over a range of variation of each parameter used in the analytical method. The choice of the range of variation is important because each real building of a given type will eventually be assessed using the same fragility curve. Fragility curves will be developed using Monte Carlo simulations. For a given building type, a set of random theoretical buildings from this type are defined and studied using the analytical method. Because each building is different, each building has a different set of threshold values associated to each damage category. Thus, the fragility curves represent a synthesis of these results.

\subsection{Methodology of drawing the fragility curves}

Fragility curves were drawn via the Monte Carlo method using MATLAB software. Four steps were followed to draw the fragility curves for each building type. The first step is to generate randomly, for each combined intervals of $E / G$ and $L / H$, n values (generally taken as 1000) of $L / H$ and $E / G$, assuming a uniform distribution for both $E / G$ and $L / H$ ratios. The second step is to vary the values of the deflection ratio from 0 to 0.01 to sweep over all the damage categories, using a step size of $10^{-5}$. The third step is

Table 4

Values of Ks/Kn relative to different types of materials used in the masonry structure.

\begin{tabular}{|c|c|c|c|c|c|c|c|c|c|c|}
\hline \multirow{2}{*}{\multicolumn{3}{|c|}{ Units of $E$ and $G$ in $\mathrm{GPa}$}} & \multicolumn{8}{|c|}{ Mortar } \\
\hline & & & \multicolumn{2}{|c|}{ Cement mortar } & \multicolumn{2}{|c|}{$\begin{array}{l}\text { Cement lime } \\
\text { mortar }\end{array}$} & \multicolumn{2}{|c|}{ Lime mortar } & \multicolumn{2}{|c|}{$\begin{array}{l}\text { Cement lime } \\
\text { mortar reinforced }\end{array}$} \\
\hline \multirow[t]{3}{*}{ Blocks } & \multirow[t]{3}{*}{$E_{u}$} & \multirow[t]{3}{*}{$G_{u}$} & $E_{m}$ & $G_{m}$ & $E_{m}$ & $G_{m}$ & $E_{m}$ & $G_{m}$ & $E_{m}$ & $G_{m}$ \\
\hline & & & 12 & 5.9 & 14 & 5 & 1.8 & 0.64 & 11.5 & 4 \\
\hline & & & $\mathrm{Ks} / \mathrm{Kn}$ & & $\mathrm{Ks} / \mathrm{K}$ & & $\mathrm{Ks} / \mathrm{Kn}$ & & $\mathrm{Ks} / \mathrm{Kn}$ & \\
\hline Clay bricks & 20 & 8.7 & 0.611 & & 0.25 & & 0.349 & & 0.273 & \\
\hline Granite & 50 & 19 & 0.539 & & 0.34 & & 0.354 & & 0.338 & \\
\hline Limestone & 45 & 18.7 & 0.526 & & 0.33 & & 0.353 & & 0.329 & \\
\hline Concrete & 30 & 11.5 & 0.603 & & 0.33 & & 0.353 & & 0.328 & \\
\hline Hollow bricks & 5 & 1.9 & 0.333 & & 0.40 & & 0.341 & & 0.418 & \\
\hline Solid brick & 16 & 6.7 & 1.069 & & 0.17 & & 0.349 & & 0.244 & \\
\hline
\end{tabular}

Table 5

Intervals of $E / G$ and $L / H$ used for determining the fragility curves - values of Ks/Kn and the percentage of openings relative to each value of $E / G$.

\begin{tabular}{|c|c|c|c|c|c|c|c|}
\hline Description of masonry (bricks and joints) & $\mathrm{Ks} / \mathrm{Kn}$ & $\begin{array}{l}\text { Percentage of } \\
\text { openings }\end{array}$ & Interval of $E / G$ & $\begin{array}{l}\text { Used interval } \\
\text { of } E / G\end{array}$ & $\begin{array}{l}\text { Interval of } \\
L / H\end{array}$ & $\begin{array}{l}\text { Geometrical description } \\
\text { (horizontal slenderness) }\end{array}$ & $\begin{array}{l}\text { Case } \\
\text { name }\end{array}$ \\
\hline Solid bricks with cement mortar & 1 & $\begin{array}{l}0-10 \% \\
10-20 \% \\
20-30 \%\end{array}$ & $\begin{array}{l}3.4<E / G<5 \\
5<E / G<8 \\
8<E / G<11\end{array}$ & $2.6<E / G<11$ & $\begin{array}{l}2-4 \\
4-6 \\
6-8 \\
8-12\end{array}$ & $\begin{array}{l}\text { Medium } \\
\text { Large } \\
\text { Very large } \\
\text { Exceptional }\end{array}$ & $\begin{array}{l}1-\mathrm{a} \\
1-\mathrm{b} \\
1-\mathrm{c} \\
1-\mathrm{d}\end{array}$ \\
\hline Solid bricks with cement lime mortar & $1 / 10$ & $\begin{array}{l}0-10 \% \\
10-20 \% \\
20-30 \%\end{array}$ & $\begin{array}{l}10<E / G<12 \\
12<E / G<16 \\
16<E / G<19\end{array}$ & $10<E / G<19$ & $\begin{array}{l}2-4 \\
4-6 \\
6-8 \\
8-12\end{array}$ & $\begin{array}{l}\text { Medium } \\
\text { Large } \\
\text { Very large } \\
\text { Exceptional }\end{array}$ & $\begin{array}{l}2-a \\
2-b \\
2-c \\
2-d\end{array}$ \\
\hline $\begin{array}{l}\text { Joints with a reduced resistance-shear } \\
\text { displacement }\end{array}$ & $1 / 20$ & $\begin{array}{l}0-10 \% \\
10-20 \% \\
20-30 \%\end{array}$ & $\begin{array}{l}17<E / G<19 \\
19<E / G<24 \\
24<E / G<28\end{array}$ & $17<E / G<28$ & $\begin{array}{l}2-4 \\
4-6 \\
6-8 \\
8-12\end{array}$ & $\begin{array}{l}\text { Medium } \\
\text { Large } \\
\text { Very large } \\
\text { Exceptional }\end{array}$ & $\begin{array}{l}3-a \\
3-b \\
3-c \\
3-d\end{array}$ \\
\hline $\begin{array}{l}\text { Joints with a very weak resistance-shear } \\
\text { displacement - sliding joint }\end{array}$ & $1 / 50$ & $\begin{array}{l}0-10 \% \\
10-20 \% \\
20-30 \%\end{array}$ & $\begin{array}{l}36<E / G<39 \\
39<E / G<46 \\
46<E / G<52\end{array}$ & $36<E / G<52$ & $\begin{array}{l}2-4 \\
4-6 \\
6-8 \\
8-12\end{array}$ & $\begin{array}{l}\text { Medium } \\
\text { Large } \\
\text { Very large } \\
\text { Exceptional }\end{array}$ & $\begin{array}{l}4-a \\
4-b \\
4-c \\
4-d\end{array}$ \\
\hline
\end{tabular}


$(2.6<\mathrm{E} / \mathrm{G}<11 ; 2<\mathrm{L} / \mathrm{H}<4)$

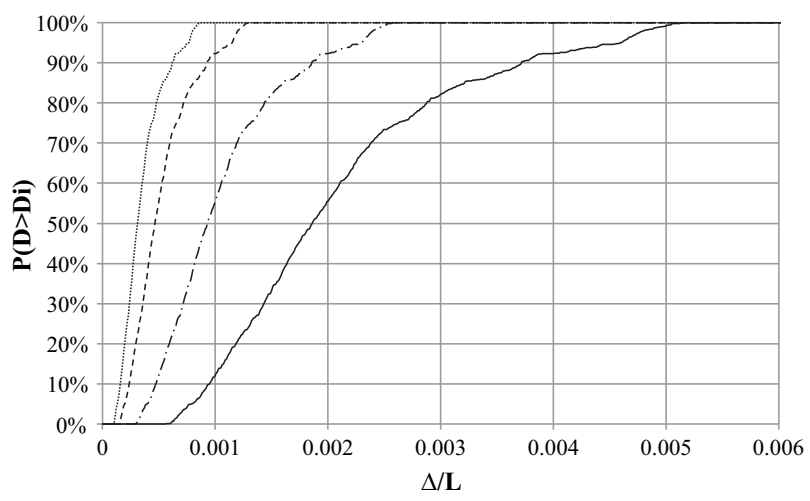

$(2.6<\mathrm{E} / \mathrm{G}<11 ; 6<\mathrm{L} / \mathrm{H}<8)$

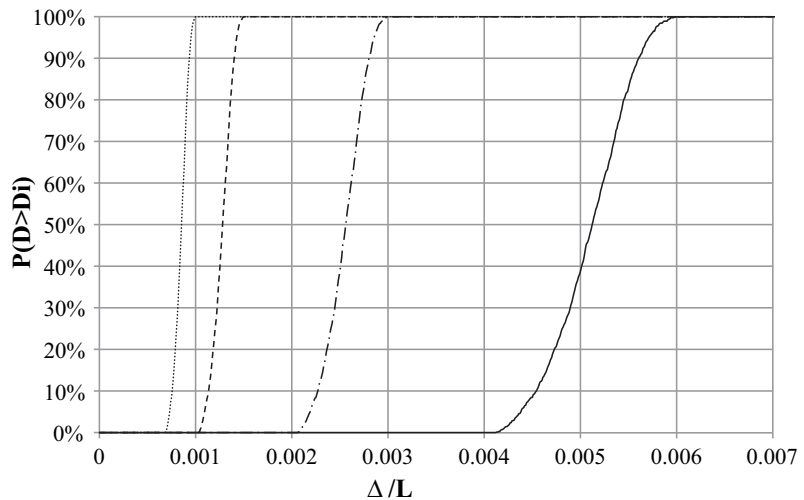

$(2.6<\mathrm{E} / \mathrm{G}<11 ; 4<\mathrm{L} / \mathrm{H}<6)$

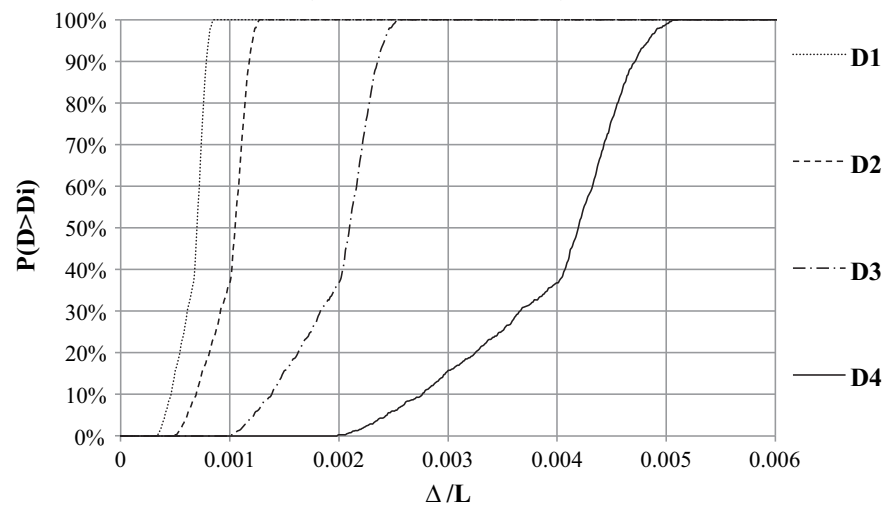

$(2.6<\mathrm{E} / \mathrm{G}<11 ; 8<\mathrm{L} / \mathrm{H}<\mathbf{1 2})$

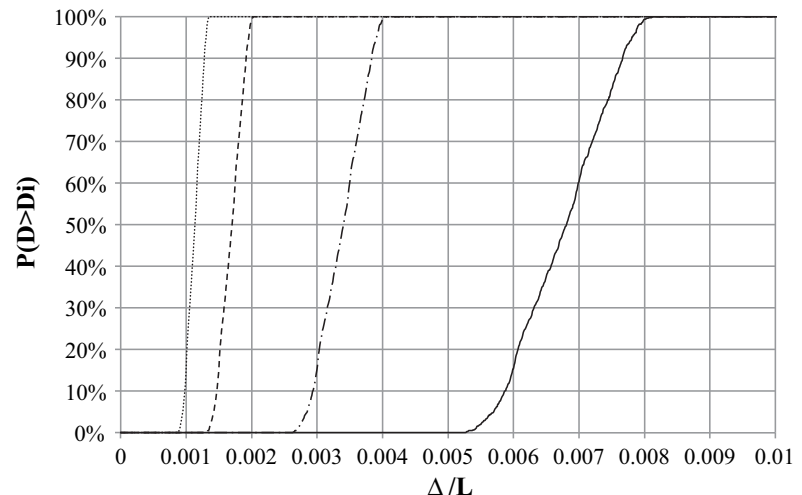

Fig. 12. Fragility curves for case $1(2.6<E / G<11)$ for all intervals of $L / H$.

$(10<\mathrm{E} / \mathrm{G}<20 ; 2<\mathrm{L} / \mathrm{H}<4)$

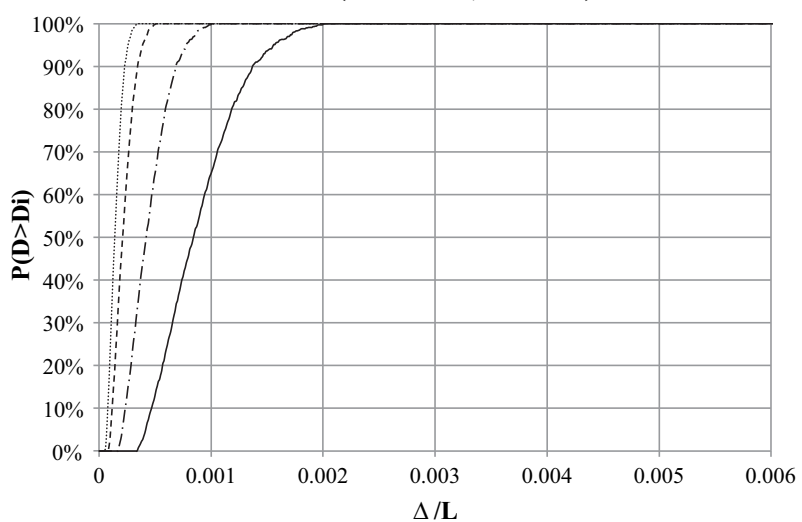

$(10<\mathrm{E} / \mathrm{G}<20 ; 6<\mathrm{L} / \mathrm{H}<8)$

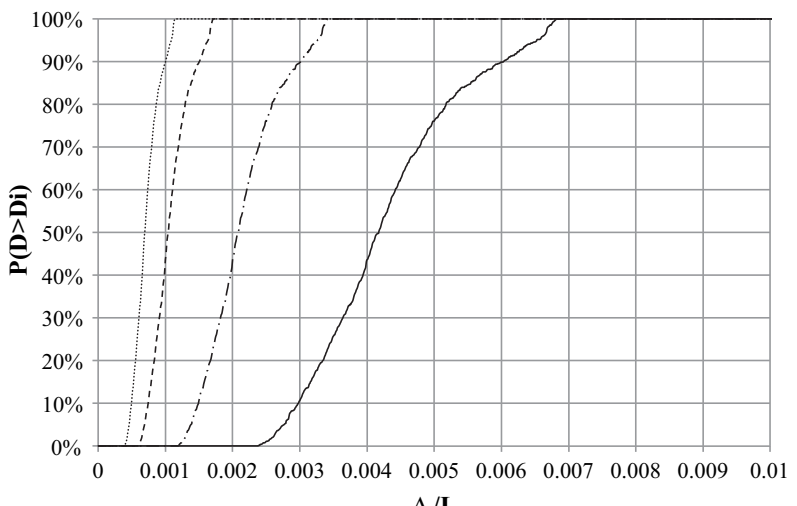

$(10<\mathrm{E} / \mathrm{G}<20 ; 4<\mathrm{L} / \mathrm{H}<6)$

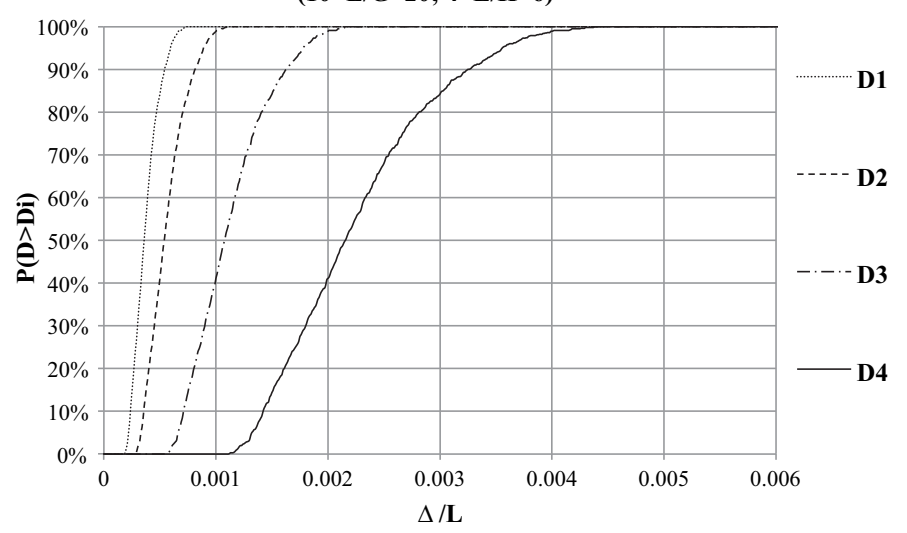

$(10<\mathrm{E} / \mathrm{G}<20 ; 8<\mathrm{L} / \mathrm{H}<12)$

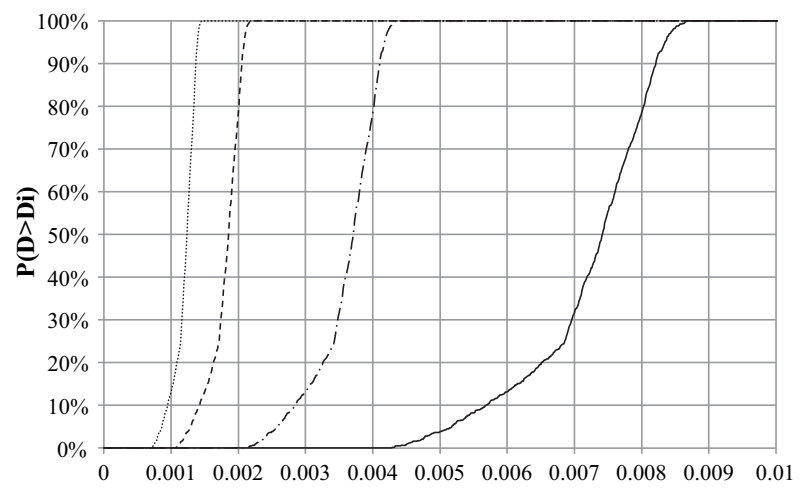

$\Delta / \mathbf{L}$

Fig. 13. Fragility curves for case $2(10<E / G<20)$ for all intervals of $L / H$. 
$(17<\mathrm{E} / \mathrm{G}<28 ; 2<\mathrm{L} / \mathrm{H}<4)$

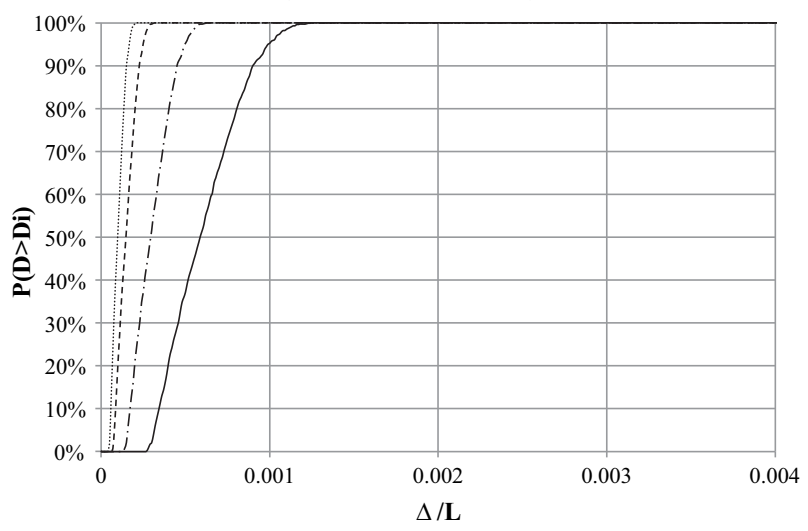

$(17<\mathrm{E} / \mathrm{G}<28 ; 6<\mathrm{L} / \mathrm{H}<8)$

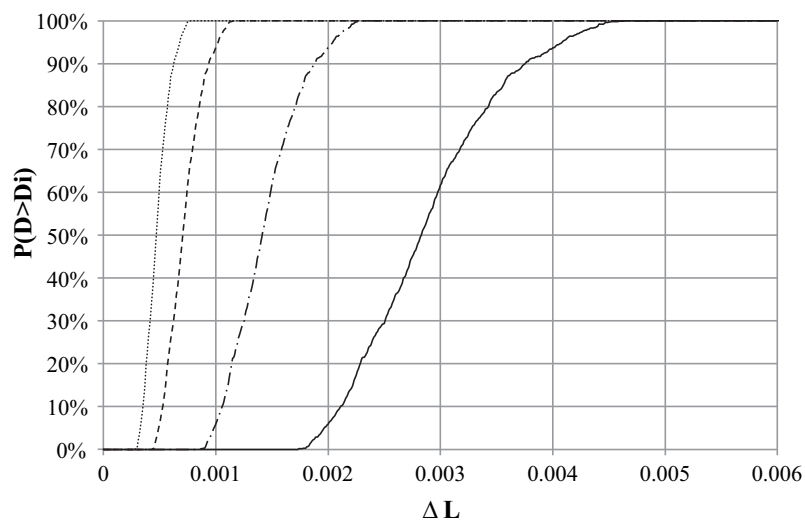

$(17<\mathrm{E} / \mathrm{G}<28 ; 4<\mathrm{L} / \mathrm{H}<6)$

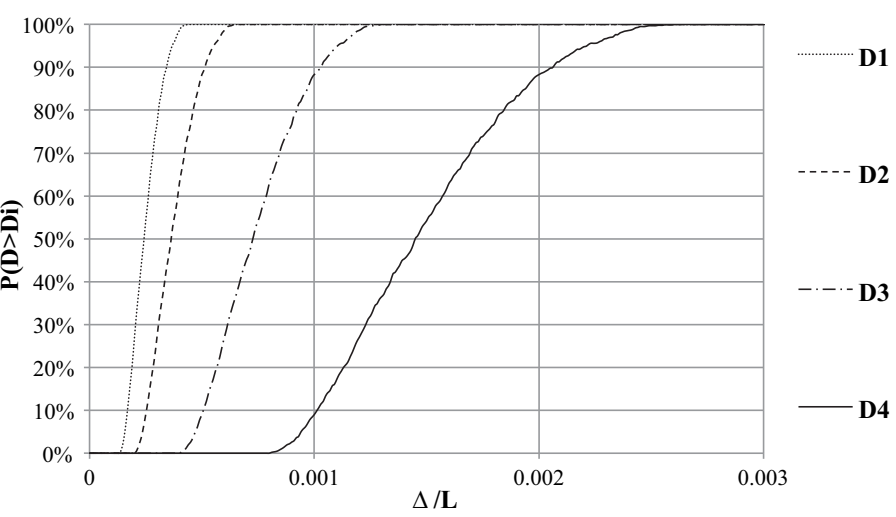

$(17<\mathrm{E} / \mathrm{G}<28 ; 8<\mathrm{L} / \mathrm{H}<\mathbf{1 2})$

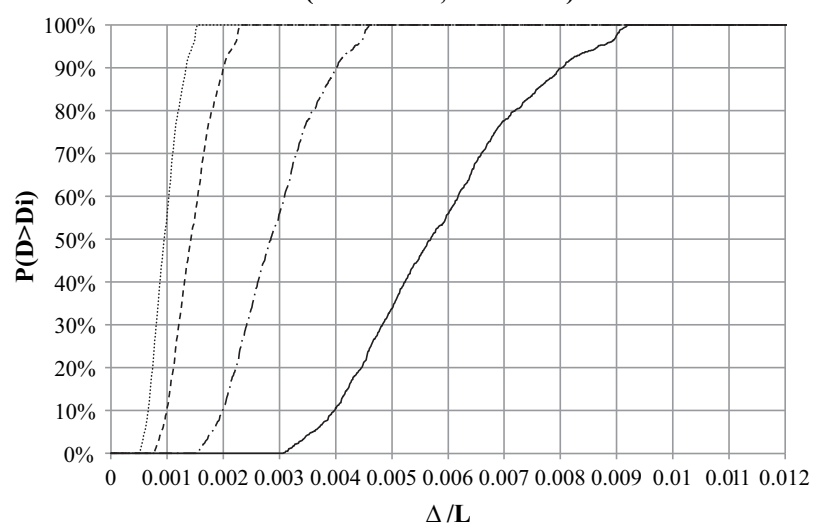

Fig. 14. Fragility curves for case $3(17<E / G<28)$ for all intervals of $L / H$.

to calculate the value of the maximal tensile strain of the structure (in bending and shear areas) for each value of the deflection ratio using Eqs. (3)-(5). This value of the tensile strain will allow us to define the damage category by comparison with the limit values of the tensile strain presented in Table 2. For each deflection ratio, 1000 damage values are then obtained. The probability of occurrence of each damage category is then calculated using Eq. (7):

$P(\mathrm{Di})=\frac{N(\mathrm{Di})}{n}$

where $N(\mathrm{Di})$ is the number of buildings appearing in the damage category $\mathrm{Di}$, and $n$ is the total number of buildings (1000). The fourth step is to plot the fragility curves for each combined interval of $E / G$ and $L / H$ by computing the probability $P(D>$ Di $)$ using Eqs. (8) and (9):

$$
\begin{aligned}
& P(\text { Damage } \geqslant D \mathrm{D})=1-P(\text { Damage }<\mathrm{Di}) \\
& P(\text { Damage }<\mathrm{Di})=\sum_{j=1}^{i-1} \frac{N(\mathrm{Dj})}{n}=\sum_{j=1}^{i-1} P(\mathrm{Dj})
\end{aligned}
$$

Fig. 8 represents the steps followed to draw the fragility curves.

The fragility curves were then drawn for both bending and shear areas. The drawn curves correspond to a neutral axis situated at the middle height of the beam section. This choice is taken because in the sensitivity analysis, the position of the neutral axis only slightly affected the values of the thresholds of the deflection ratio. First, the curves are drawn for the two critical areas of bending and shear, as shown in the example in Fig. 9a that corresponds to buildings with $3.4<E / G<5$ and $2<L / \mathrm{H} 4$. The final curves are then the envelopes of the maximum probability between the two critical states (Fig. 9b).

\section{Typologies of masonry structures - fragility curves for different masonry building cases}

To develop a building typology, we chose to divide the intervals of $E / G$ and $L / H$ used in the sensitivity analysis into several intervals so that each combined interval of $E / G$ and $L / H$ may represent a specific typology of in-situ masonry buildings.

\subsection{Intervals of the $\mathrm{L} / \mathrm{H}$ ratio}

For the choice of intervals of $L / H$, various references divide the typologies of buildings according to their length and height.

Saeidi [21] developed a typology for buildings in a mining subsidence area using different parameters, where length is one of these parameters. He divided the buildings into five categories according to their length: small $(<10 \mathrm{~m})$, medium $(11-20 \mathrm{~m})$, large (21-30 m), very large (31-40 m) and exceptional ( $\geqslant 41 \mathrm{~m})$. In addition to the length of buildings, he noted that, according to properties of the basin of Lorraine (France), most of the buildings have one or two floors, i.e., a height of 5-9 $\mathrm{m}$. This information leads to the ratios of horizontal slenderness $L / H$, as presented in Table 3 .

\subsection{Intervals of the $E / G$ ratio}

The partition of the interval of $E / G$ was based on a numerical study performed by Son and Cording [22]. Son and Cording [22] presented the relationship between the equivalent $E / G$ ratio of a homogeneous and elastic beam and the opening percentage (windows and doors) of the total wall area for different values of the shear to normal joint stiffness ratio $\mathrm{Ks} / \mathrm{Kn}$ (a joint corresponds to mortar in the masonry structure). They used UDEC (Universal 
$(36<\mathrm{E} / \mathrm{G}<52 ; 2<\mathrm{L} / \mathrm{H}<4)$

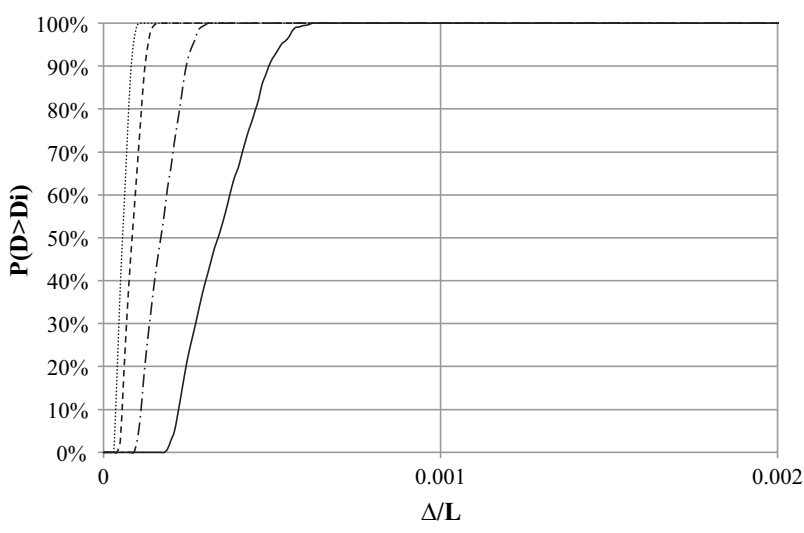

$(36<\mathrm{E} / \mathrm{G}<52 ; 6<\mathrm{L} / \mathrm{H}<8)$

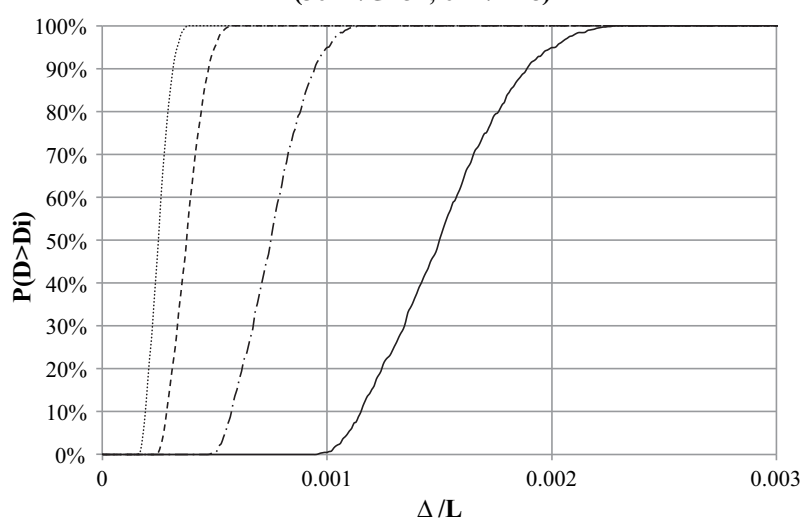

$(36<\mathrm{E} / \mathrm{G}<52 ; 4<\mathrm{L} / \mathrm{H}<6)$

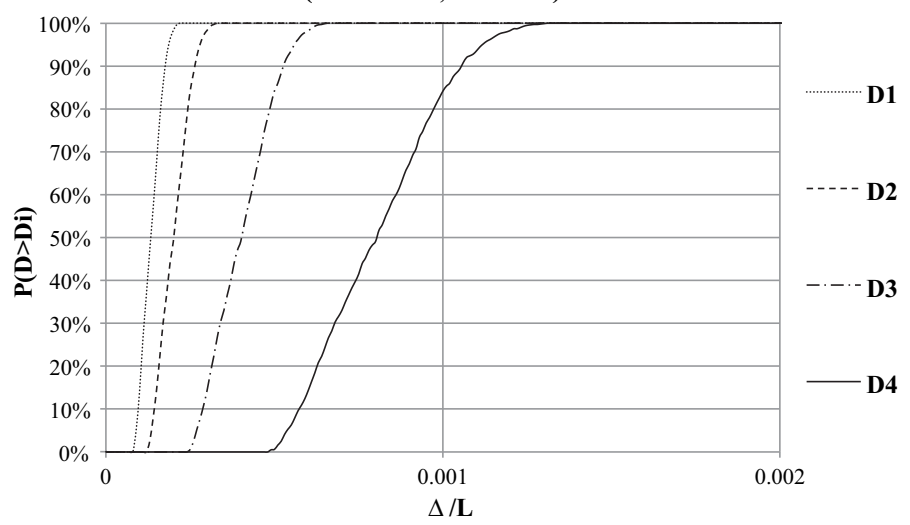

$(36<\mathrm{E} / \mathrm{G}<52 ; 8<\mathrm{L} / \mathrm{H}<12)$

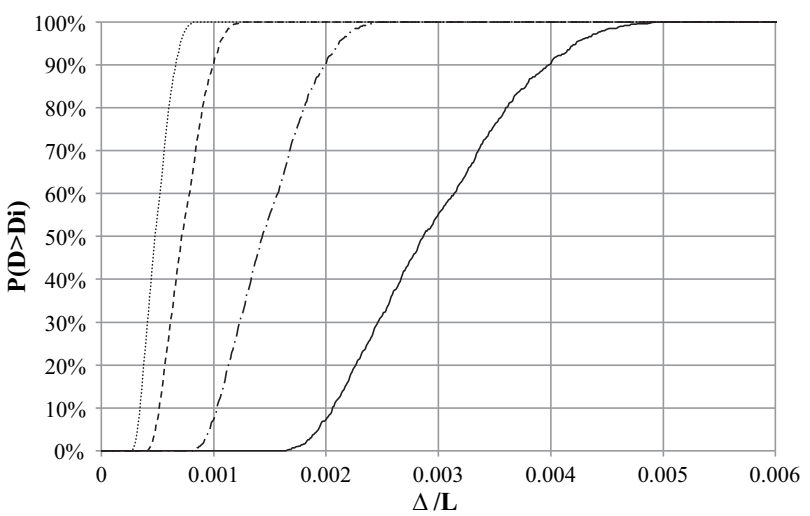

Fig. 15. Fragility curves for case $4(36<E / G<52)$ for all intervals of $L / H$.

Distinct Element Code, ITASCA, 2000) and an analytical method to estimate the stiffness of masonry structures with controlled parameters of window opening and brick/mortar joint properties.

Before explaining the choice of the intervals, this paragraph briefly describes the distinct element method to explain the signification of the shear and normal stiffness of the joints. At each contact between two blocks, the mechanical interaction between blocks is represented by force-displacement relations with normal stress $\left(\sigma_{n}\right)$ and displacement component and shear stress $(\tau)$ and tangential displacement component. Contact displacements are defined as the relative displacement between two blocks at the contact point. In the elastic range, contact forces and displacements are related through the contact stiffness parameters (normal and shear) (Fig. 10); in addition, for failure or elasto-plastic behaviour, a failure criterion is considered, with the Mohr-Coulomb criterion being a function of the cohesion and friction angle. Many authors studied numerical, physical and experimental models of masonry structures in order to characterise their behaviour due to different load cases (in plane loads, out of plane loads) [2731]. Bui [27] discussed the behaviour of masonry walls in the loading case of a uniform out of plane pressure, due to, experiments and numerical modelling. Ngheim et al. $[28,29]$ studied the effect of sinkhole on the building, by using a physical model, taking into account the soil structure interaction. Anastasios et al. [30] studied the numerical prediction of the compressive response of masonry, by considering a typology that consists of solid units, brick, and mortar of lower strength and higher deformability. Haach et al. [31] studied the behaviour of masonry walls subjected to horizontal loadings, due to the influence of flanges. He carried out a parametric analysis to define the influence of some parameters on the behaviour of the masonry wall, such as geometry, boundary condi- tions, and the angle of the horizontal loading application. In fact, the focus of this part is not the behaviour of the masonry structure; it is the values of the shear and normal stiffness of the joints that will be used to define the typologies in order to draw the fragility curves.

Son and Cording [22] demonstrated that the value of Ks/Kn and the percentage of openings affect the values of $E / G$. For example, $E$ / $G$ varies between 3.4 and 11 for $\mathrm{Ks} / \mathrm{Kn}$ equal to 1 and a percentage of openings increasing from $0 \%$ to $30 \%$. For Ks/Kn equal to $1 / 50, E / G$ varies between 36 and 52 for a percentage of opening area increasing from $0 \%$ to $30 \%$.

From Fig. 11, four intervals of $E / G$ can be used to draw the fragility curves: $(3.4 ; 11),(10 ; 19),(17 ; 28)$ and $(36 ; 52)$. Each interval represents a case of the Ks/Kn ratio, with a variation of the percentage of openings from $0 \%$ to $30 \%$.

To be more descriptive, we proceed with a study of the choice of the ratio of $\mathrm{Ks} / \mathrm{Kn}$ to explain its significance. Table 4 presents the meaning of each value of $\mathrm{Ks} / \mathrm{Kn}$ ratio.

Lourenço [33] suggested the following equations to evaluate the values of $\mathrm{Ks}$ and $\mathrm{Kn}$ as a function of the properties of the masonry blocks and of the mortar used (Eqs. (10) and (11) [33]).

$$
\begin{aligned}
\mathrm{Kn} & =\frac{E_{u} E_{m}}{h_{m}\left(E_{u}-E_{m}\right)} \\
\mathrm{Ks} & =\frac{G_{u} G_{m}}{h_{m}\left(G_{u}-G_{m}\right)}
\end{aligned}
$$

where $E_{u}$ and $G_{u}$ represent the Young's modulus and the shear modulus, respectively, of the block units. $E_{u}, G_{u}$ and $h_{m}$ represent the Young's modulus, the shear modulus and the thickness of the mortar, respectively. 

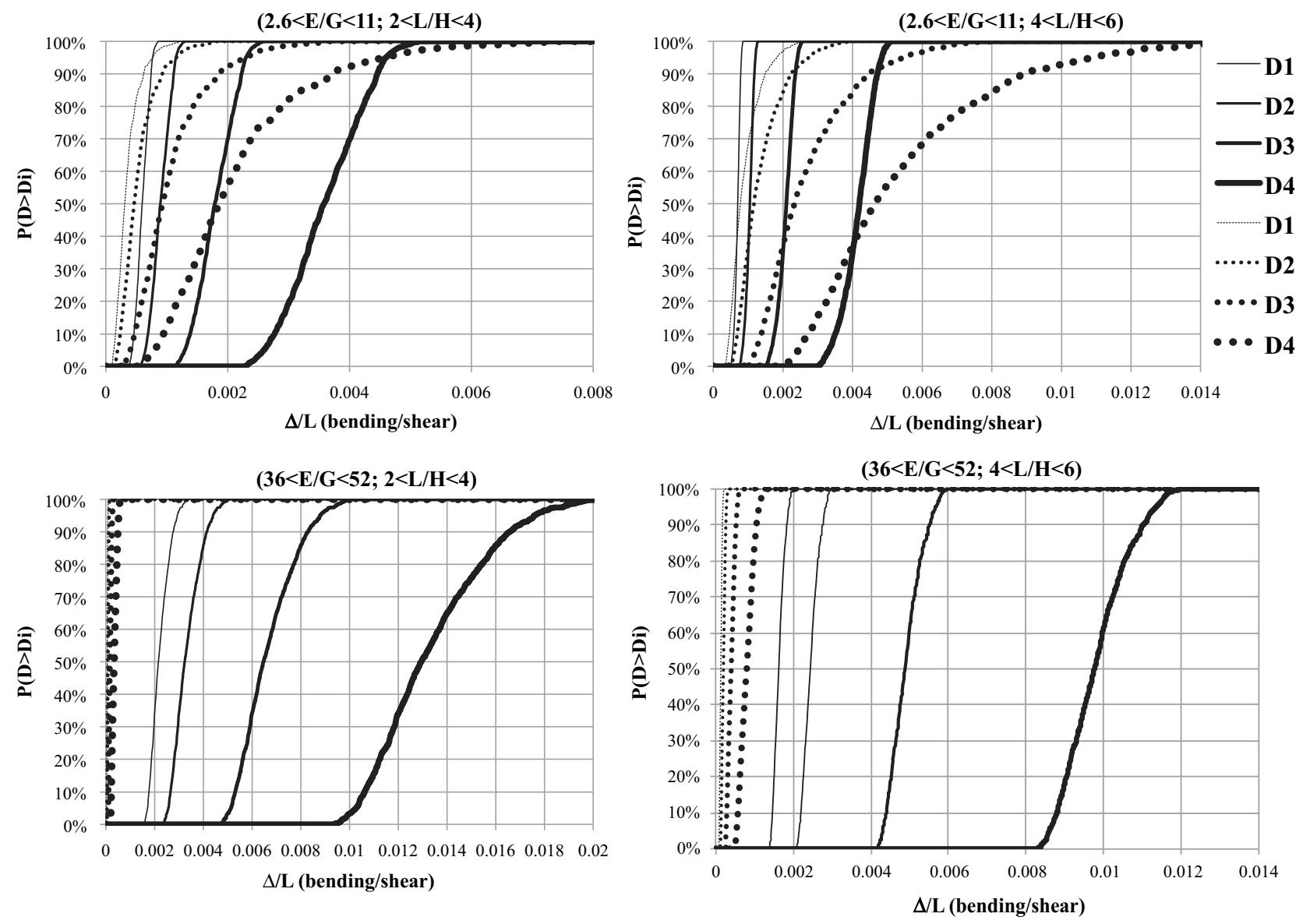

Fig. 16. Effect of $E / G$ and $L / H$ on the dominant fragility curves between the bending (b) and shear (s) critical states.

The equations provided by Lourenco [33] are used hereafter to compute the ratios of $\mathrm{Ks} / \mathrm{Kn}$ for different masonry models (various mortar types or block types). Many types of mortar (cement, cement lime, lime, and reinforced) and of blocks (clay bricks, granite, limestone, concrete, hollow bricks, and solid bricks) used in the construction of masonry buildings were found. Table 4 presents the values of the ratio $\mathrm{Ks} / \mathrm{Kn}$ for a selection of blocks with different types of mortar. The ratio Ks/Kn was obtained using Eq. (12). This ratio appears to be independent of the thickness of the mortar.

Ks $G_{u} G_{m}\left(E_{u}-E_{m}\right)$

$\frac{\mathrm{Kn}}{\mathrm{Kn}}=\frac{G_{u} G_{m}\left(E_{u}-E_{m}\right)}{E_{u} E_{m}\left(G_{u}-G_{m}\right)}$

From Table 4, a value of Ks/Kn equal 1 refers to a masonry building constructed of solid bricks and cement mortar, and the value of $\mathrm{Ks} / \mathrm{Kn}$ equal to $1 / 10$ refers to masonry constructed by solid bricks and cement lime mortar. To explain the low values of $\mathrm{Ks} / \mathrm{Kn}$ of $1 / 20$ and $1 / 50$, one can consider that these values represent a masonry building having a weak resistance to the shear displacement. In other words, these low values may refer to a masonry building for which the shear displacement may be obtained with low effort (Raffard [34] used the term of "sliding interface" for a $\mathrm{Ks} / \mathrm{Kn}=1 / 100)$.

Finally, we proposed implementing the intervals of $E / G$ and $L / H$ presented above to draw the fragility curves and determined the significance of each interval. As a result, Table 5 presents the final assumptions used to draw the fragility curves. The columns of the intervals of $E / G$ and $L / H$ of Table 5 were then used to proceed in our probabilistic study. The choice of 2.6 for the lower value of $E / G$ for the first case corresponds to an isotropic behaviour with a Poison's ratio equal to 0.3 for the masonry building.

After defining the four cases of masonry buildings, fragility curves are drawn, using the methodology presented in Section 4, for each case (Figs. 12-15). The presented curves in Figs. 12-15 are the resulting curves related to the critical bending and shear area, obtained by taking the maximum probability for each damage, relative to each value of deflection ratio, between the two cases of bending and shear.

\subsection{Discussion of the fragility curves}

Many important findings can be obtained from these fragility curves. These curves allow the visualisation of the probability of being classified in a specified damage category once knowing the values of the deflection ratio of the masonry building (i.e., the differential settlement subjected by the building) and the typology of the building.

First, the threshold value of the deflection ratio at which the probability $P(D>\mathrm{Di})$ becomes greater than zero can be found.

When increasing the ratio $E / G, P(D>\mathrm{Di})$ is observed to become greater in the shear area than in the bending area for the same value of the deflection ratio. In other words, when $E / G$ increases, these curves refer to the deflection ratio due to the tensile strain in shear area, which becomes more critical than in the bending area. This result agrees with the result obtained by the sensitivity analysis described previously for the effect of $E / G$ on the critical state between the bending area and the shear area. 


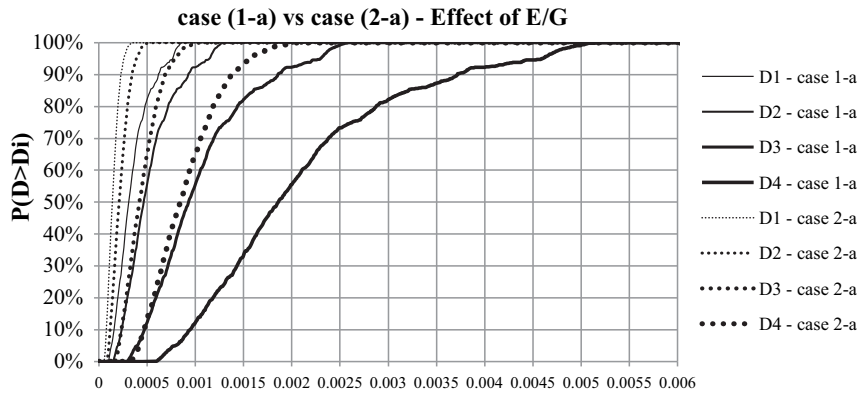

$\Delta / \mathbf{L}$ (bending/shear) - (a)

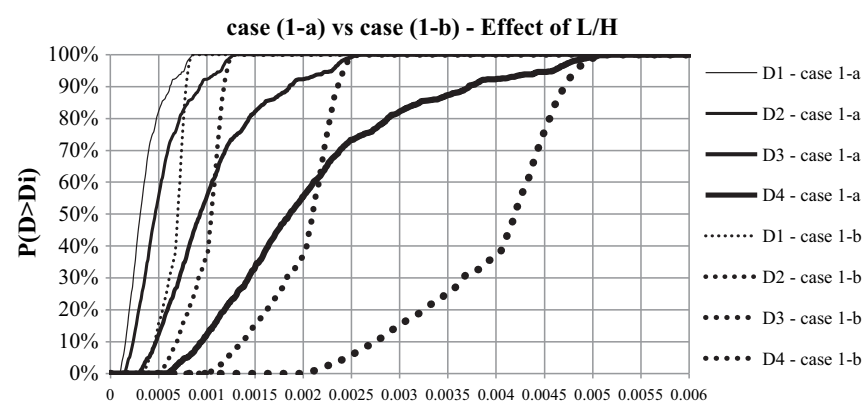

$\Delta / \mathbf{L}$ (bending/shear) - (b)

Fig. 17. (a) Effect of $E / G$ for a constant $L / H$ - (b) effect of $L / H$ for a constant $E / G$.

For the first two intervals of $E / G(2.6<E / G<11$ and $10<E /$ $G<20$ ), the increase of $L / H$ corresponds to the bending area becoming more critical. In other words, as long as the interval of $E / G$ is low, the probability of being in a defined damage category is greater for the bending area than that of the shear area (Fig. 16, case of $2.6<E / G<11$ ).

By increasing the interval of $E / G(17<E / G<28$, and $36<E /$ $G<52$ ), the shear strain becomes critical. In other words, the probability of each damage category is greater in the cases of shear than of the bending for high ranges of $E / G$, even with an increasing ratio of $L / H$ (Fig. 16 , case of $36<E / G<52$ ).

To study the effect of $L / H$ and $E / G$ separately, the curves of cases 1-a and 2-a are drawn to show the effect of $E / G$ (Fig. 17a), and the curves of cases 1 -a and 1-b are drawn to show the effect of $L / H$ (Fig. 17b). From Fig. 17a, when the ratio $E / G$ increases, the probability to reach each of the damage categories increases for the same value of deflection ratio. Additionally, from Fig. 17b, when the ratio of $L / H$ increases, the probability to reach each of the damage categories decreases for the same value of the deflection ratio.

These fragility curves may be compared with other studies that try to relate the effect of the building properties on the damage assessment, and try to study the uncertainty of this assessment. Giardiana et al. [26] recently used numerical models to assess the damage as a function of the maximum crack width noted in Table 2. Most of their models are characterised by a $L / H$ ratio between 1 and 2, with percentage of façade openings between $0 \%$ and $30 \%$, Young's modulus of $3000 \mathrm{MPa}$. Several other parameters are used that cannot be easily compared with parameters used in this study as the tensile strength, behaviour of the base interface, orientation of the building. On the whole, the building types that are the most comparable with their models are case 1-a and 2-a with an $L / H$ ratio between 2 and 4 and $E / G$ ratio between 2.6 and 19 because of the joints stiffness or percentage of openings. First Giardiana et al. [26] find that the maximum damage occurs for deflection ratio between $1 \cdot 10^{-3}$ and $3 \cdot 10^{-3}$ that may be comparable with those got in this study (Fig. 7). Secondly, they found that the percentage of openings is a significant factor since for a given deflection ratio of $1 \cdot 10^{-3}$, the damage increases from grade 1 to grade 6 when the percentage of openings increases from $0 \%$ to $30 \%$. In the actual analytical model, the percentage of openings is correlated to the $E / G$ ratio. This variation of $E / G$ is entirely taken into account when developing fragility curves for each case, and as the variation of $E / G$ in this analytical study implicitly indicates the variation of the percentage of openings, it is not possible to directly compare the influence of this single parameter between the two studies. However, sensitivity analysis presented in Fig. 6 shows that for the same given deflection ratio of $1 \cdot 10^{-3}$, for a $L /$ $H$ ratio between 1 and 2 and $E / G$ between 3.4 and 12.5 (influence of openings, cf. Fig. 11), the damage is between category 2 and 4 (Fig. 6) which is a comparable range that the one got by Giardiana et al. [26].
Finally, in this paper, we covered a large ratio of building typology allowing the assessment of damage category.

\section{Conclusion}

First, this paper presented different threshold values of the defection ratio used to evaluate the damage level of the masonry buildings due to differential settlements.

Second, to study the variation of the threshold values of the deflection ratio, a comprehensive sensitivity analysis of the effect of the properties of the masonry buildings on this parameter was conducted. The analytical method of Burland et al. [5] based on beam theory was used. The threshold values of the deflection ratio were observed to have a range of variation that depends on the mechanical and geometrical properties of the masonry building. The length to height ratio and the ratio of the Young's modulus to the shear modulus of the masonry structure were demonstrated to have a considerable effect on the thresholds of the deflection ratio. The critical areas of shear and bending were observed, and the effect of the length to height ratio and the ratio of the Young's modulus to the shear modulus on these critical areas was highlighted. In addition, a transition from a critical area of shear to a critical area of bending was observed when increasing the $L / H$ ratio. The opposite transition was noted when increasing the $E / G$ ratio. The sensitivity study demonstrated that each value of the deflection ratio might refer to different categories of damage as a function of the properties of the masonry building. The variability of the threshold values of the deflection ratio obtained from the analytical study was found to be consistent with the observed in the literature. As a result, it can be concluded that two buildings having different properties may be damaged differently, even if they are subjected to the same settlement. These results will be useful for draw fragility curves in future probabilistic studies.

The objective of the fragility curves is to provide the probability to suffer a damage category for each building that falls into a given typology developed in this paper, once knowing its deflection ratio. These typologies refer to the geometrical properties of the building (length-to-height ratios from 2 to 8 ) and the mechanical properties of the building (equivalent ratios of the Young's modulus to the shear modulus from 2.6 to 52 ) in relation to the masonry components (blocks and mortar) that govern its mechanical behaviour. From these curves, the minimum value of the thresholds of the deflection ratio to achieve a probability of damage greater than zero (i.e., $P(D>\mathrm{Di})>0$ ) can be determined as a function of the building properties. These fragility curves will cover the uncertainties related to the geometrical and mechanical properties used to model a real masonry building as a simple anisotropic beam. The final results provide the probability of occurrence of each of the damage categories and thus provide a more accurate assessment of the damage category of the masonry buildings. 


\section{References}

[1] McGuire RK. Seismic hazard and risk analysis. EERI Earthquake Engineering Research Institute; 2004.

[2] Hazus. Multi-hazard loss estimation methodology earthquake model, technical and user manuals. Washington, DC: Federal Emergency Management Agency; 1999 [chapter 2].

[3] Spence RJS, Kelman I, Baxter PJ, Zuccaro G, Petrazzuoli S. Residential building and occupant vulnerability to tephra fall. J Nat Hazards Earth Syst Sc 2005;5:477-94.

[4] Saeidi A, Deck O, Verdel T. Development of buildings vulnerability functions in subsidence regions from empirical methods. Eng Struct 2009;31:2275-86. http://dx.doi.org/10.1680/geot.9.P.028.

[5] Burland JB, Broms BB, De Mello VFB. Behaviour of foundations and structures. In: 9th int conf on soil mechanics and foundations engineering, Tokyo, vol. 2; 1977. p. $495-546$

[6] Boscardin MD, Cording EJ. Building response to excavation-induced settlement. J Geotech Eng 1989;115(1).

[7] Boone SJ. Assessing construction and settlement-induced building damage: a return to fundamental principles. In: Proceedings, underground construction, institution of mining and metallurgy, London; 2001. p. 559-70.

[8] Giardina G, Hendriks Max AN, Rots Jan G. Sensitivity study on tunneling induced damage to a masonry facade. Eng Struct 2015;89:111-29. 15 April 2015.

[9] Hong H, Guo-Wei M, Yong L. Damage assessment of masonry infilled RC frames subjected to blasting induced ground excitations. Eng Struct 2002;24 (6):799-809.

[10] Deck O. Étude des conséquences des affaissements miniers sur le bâti. Thèse de doctorat, Institut National Polytechnique de Lorraine, Nancy - France; 2002.

[11] Bhattacharya S, Singh M. Proposed criteria for subsidence damage to buildings. In: Rock mechanics in productivity and protection, 25st symposium on rock mechanics; 1984. p. 747-55.

[12] Pellisier JP, Williams AAB. The cellular raft foundation for buildings over mined areas. In: COMA, symposium on construction over mined areas, Pretoria, South Africa, May 1992; 1992. p. 125-30.

[13] Pellisier JP, Williams AAB, Lunt BG. Predicting and assessing undermininginduced distress in typical south african buildings. In: COMA, symp on construction over mined areas, Pretoria, South Africa, Mai 1992; 1992. p. 11723.

[14] Ji-Xian C. The effects of mining on buildings and structural precautions adopted. In: 3e int conf large ground movements and structures (Cardiff); 1985. p. 404-19.

[15] Bruhn RW, McCann WS, Speck RC, Gray RE. Damage to structures above active underground coal mines in the northern Appalachian coal field. In: First int conf on stability in underground mining; 1982. p. 1022-46 [chapter 47].

[16] Mine subsidence engineering consultants - mine subsidence damage to building structures - revision A, August 2007.

[17] Burland JB. Assessment of risk of damage to buildings due to tunnelling and excavation. Earthquake geotechnical engineering, Editions Ishihara, Balkema; 1995. p. 1189-201.
[18] Ricceri G, Soranzo M. An analysis on allowable settlements of structures. Rivista Italiana di Geotechnica 1985;4:177-88.

[19] Klepikov SN. Performance criteria, allowable deformations of buildings and damages. Rapport général, discussion de la session 28, 12eme congrès international de mécanique des sols et de travaux de fondation, Rio de Janeiro; 1989. p. 2735-44 [traduit du russe].

[20] Burland JB, Wroth CP. Settlement of buildings and associated damage. In: Conf settlement of structures; 1974 . p. 611-54.

[21] Saeidi A. La vulnérabilité des ouvrages soumis aux aléas mouvements de terrains; développement d'un simulateur de dommages-Doctorate thesis, Institut National Polytechnique de Lorraine, Nancy - France; 2010.

[22] Son M, Cording EJ. Evaluation of building stiffness for building response analysis to excavation-induced ground movements. J Geotech Eng ASCE 2007;133(8):995-1002.

[23] Saeidi A, Deck O, Verdel T. Development of buildings vulnerability functions in subsidence regions from analytical methods. Géotechnique 2012;62 (2):107-20.

[24] Singh B. The response of buildings to excavation-induced ground movements. Ph.D., thesis, Univ Of Illinois at Urbana-champaign Urbana, III; 1973.

[25] Boone SJ. Ground-movement related building damage. J Geotech Eng ASCE $1996 ; 122(11): 886-96$.

[26] Giardina G, Hendriks M, Rots J. Damage functions for the vulnerability assessment of masonry buildings subjected to tunneling. J Struct Eng 2015;141(9):04014212.

[27] Bui TT. Etude expérimentale et numérique du comportement des voiles en maçonnerie soumis à un chargement hors plan - Thèse de doctorat, Institut des Sciences Appliquées de Lyon; 2013.

[28] Ngheim HL. Impact des fontis sur le bâti: évaluation de la vulnérabilité par modélisation physique - Thèse de doctorat, Université de Grenoble - France; 2015.

[29] Ngheim HL, Emeriault F, Al Heib M. Assessment of damage induced in masonry structures by soil subsidence using physical modeling. In: Proc, 9th int Masonry conf, Portugal; 2014.

[30] Anastasios D, Pere R, Climent M. Numerical prediction of the behaviour, strength and elasticity of masonry in compression. Eng Struct 2015;90:15-28. 1 May 2015.

[31] Haach Vladimir G, Ramalho Marcio A, Correa Marcio RS. Parametric study of unreinforced flanged masonry walls subjected to horizontal loading through numerical modeling. Eng Struct 2013;56:207-17. November 2013.

[32] Cook D. Studies of settlement and crack damage in old and new facades. In: Proc 3rd int Masonry conf, London; 1994. p. 203-11.

[33] Lourenço PB. Computational strategies for masonry structures - Doctorate thesis - Technical University of Delft; 1996.

[34] Raffard D. Modélisation de structures maçonnées par homogénéisation numérique non linéaire: application aux ouvrages d'intérêt archéologique. France: Institut National Polytechnique de Lorraine Nancy; 2000.

[35] Stacey, Bakker. The erection or construction of buildings and other structures on undermined ground. In: COMA, symposium on construction over mined areas, Afrique du Sud; 1992. p. 282-288. 